\title{
Screening for macular disorders: the optometrist's perspective
}

This article was published in the following Dove Press journal:

Clinical Optometry

18 March 2015

Number of times this article has been viewed

\section{Ann E Elsner \\ Brett J King \\ School of Optometry, Indiana University, Bloomington, IN, USA}

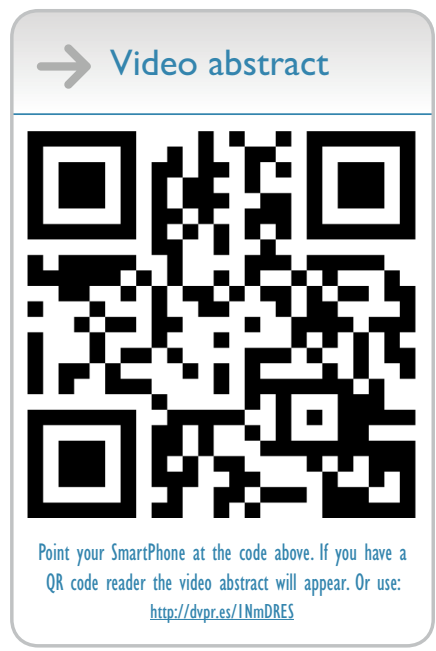

Correspondence: Ann E Elsner School of Optometry, Indiana University, 800 East Atwater Avenue, Bloomington, IN 47405, USA

Tel + I 8I2856 I500

Email aeelsner@indiana.edu
Abstract: Macular screening services can take many forms, offering a variety of roles for optometrists. The need for screening has been demonstrated in industrialized and developing nations alike. Populations of particular interest for macular screening services include individuals at high risk for diabetes, not just diagnosed diabetics, since a significant proportion of those with diabetes do not realize it. Individuals who know they have diabetes are frequently not examined at the recommended intervals. Related populations include patients with a high likelihood of retinal vascular disease and high blood pressure. A second population is older individuals, who are at risk for age-related macular degeneration and degenerative myopia, key causes of vision loss depending upon geographic location and ethnicity. Images showing the complexity of lesions from diabetic retinopathy, age-related macular degeneration, and degenerative myopia illustrate the challenges of screening and classification. A third population to be screened is the large pediatric one. While many children are at risk for developing myopia, which could lead to high myopia, the risk of myopia and retinal damage is far more common in individuals who had low birth weight or premature birth. A variety of types of screening instrumentation are discussed in terms of practicality of use and cost. The technical challenges in populations with dark eyes, small pupils, and poor anterior-segment media are discussed. We discuss the wealth of screening strategies, from permanent sites with trained staff and expert graders to planned campaigns that target specific populations. Successful screening systems include instrumentation that is used within its limits, feedback and supervision during screening and grading, and clear pathways for referral for a complete examination or treatment.

Keywords: vision screening, diabetic retinopathy, diabetic macular edema, age-related macular degeneration, degenerative myopia, pediatric vision screening

\section{Why screen?}

Early detection is the key to treatment success in several macular conditions. Visual acuity (VA) is the primary measure of macular function in population-based studies of visual impairment, clinical trials that assess treatment, natural history studies, and scientific studies. VA is neither a sensitive nor a specific measure of a particular macular disorder, and certainly does not indicate the extent of early cone damage in either patients with diabetes or age-related macular degeneration (AMD). ${ }^{1-3}$ However, VA is familiar, universally recognized, and often used in macular screening. Uncorrected refractive error is often reported as the main cause of visual impairment in populations with limited access to eye care. ${ }^{4}$ This wide-scale lack of proper refraction can confound the results of screening for macular disorders and mask progressive disease. 
The refinements provided by the measurement of VA through a pinhole or performing a refraction to reach the best-corrected VA may not be part of screening protocols. Therefore, care is needed when a large proportion of the sample has uncorrected refractive error, in aspects ranging from providing immediate follow-up care to planning unmet needs for services for treatment of macular disease.

Moderate and severe vision impairment (MSVI) is defined as VA in the better eye lower than $6 / 18$ but at least $3 / 60$ at presentation, ${ }^{4}$ which corresponds to worse than 20/60 in Snellen notation, 0.33 in decimal notation, and 0.5 on the $\log$ MAR scale. The use of $\log$ MAR, which is the logarithm of the minimum angle of resolution, has been widely used in both treatment and low-vision studies. ${ }^{5}$ Blindness is defined as worse than $3 / 60$ (or $6 / 120$ ), 20/400, 0.05 , or a $\log$ MAR of 1.3. Blindness may also be defined as a visual field of less than $10^{\circ}$ in the better-seeing eye.

Globally, approximately $32,400,000$ people were considered blind in 2010, and 191,000,000 people had MSVI, ${ }^{4,6}$ but many of the screening studies were limited to adult populations. For a sophisticated model incorporating previous population-based studies and population aging for the US that includes both children and adults, new cases of vision impairment are estimated to be $240,000 .^{7}$

A major portion of these patients with vision loss have retinal and choroidal disease, as discussed herein. Diabetic retinopathy (DR) and diabetic macular edema (DME) are already the primary causes of vision loss in working adults, although the effect of refractive error must be considered in some locations, and cases of diabetes-related vision loss are likely to increase significantly because diabetes prevalence is doubling worldwide. ${ }^{8,9}$ While DR is a recognized focus of macular screening services by primary care providers and eye care providers (Figure 1), key causes of damage to macular function also include AMD (Figures 2 and 3), degenerative myopia (Figures 4 and 5), retinopathy of prematurity (ROP), hereditary retinal degenerations, and damage to the central $6^{\circ}$, due to glaucoma that is detectable with high-density perimetry or optical coherence tomography (OCT) ${ }^{10,11}$ Evidence of the enormity of the problem of visual impairment has been generated, and now solutions must be fitted to match populations at risk for visual impairment.

The success of macular screening depends upon the methodology and goals for screening, especially when considering the large differences in the populations to be screened and the resources for referral. Three broad categories of individuals who are screened include pediatric populations, potential cases of DR, and older individuals.

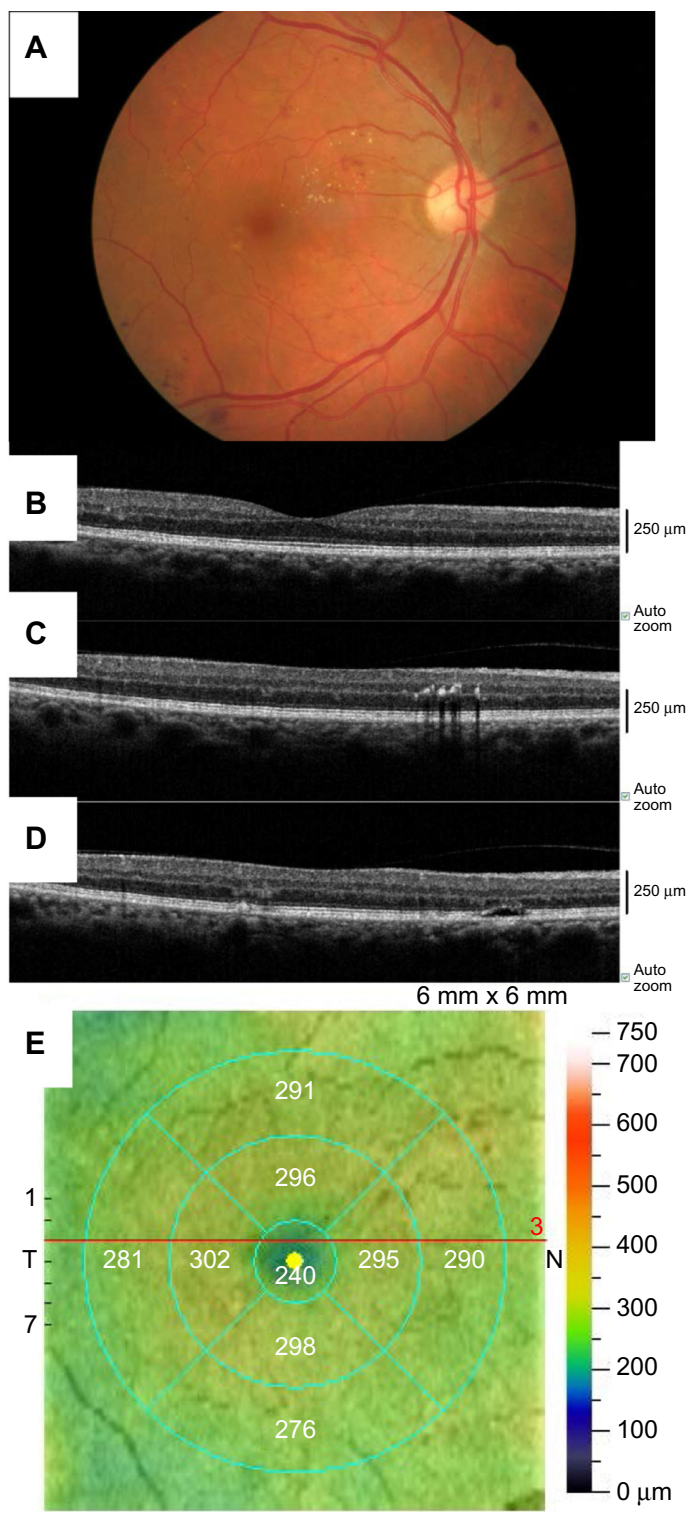

Figure I DR and DME, recruited for screening in an underserved population of diabetic patients in Alameda County, CA, USA.

Notes: (A) Nonmydriatic color fundus photograph, showing numerous microaneurysms, hemorrhages, IRMA, and hard exudates within I disk diameter of the fovea. The foveal center in this eye is relatively free of pathology, and the patient might experience visual symptoms insufficient to lead to seeking an eye examination. (B) SD-OCT scan of $6 \mathrm{~mm}$ at the patient's fixation, showing that the foveal region is neither excessively thickened nor thinned. (C) SD-OCT scan, but superior to the fovea, showing hard exudates. (D) SD-OCT scan, but inferior to the fovea, showing disruption to the ONL and other photoreceptor layers. (E) Thickness map computed from the SD-OCT scan covering, centered at the patient's fixation. Clearly, there is not abnormal retinal thickening at the center of the macula, despite the evident hard exudates and edema near the fovea that is seen in the color photograph and the individual scans.

Abbreviations: DR, diabetic retinopathy; DME, diabetic macular edema; IRMA, intraretinal microvascular abnormality; SD-OCT, spectral domain optical coherence tomography; ONL, outer nuclear layer.

Examples of these include screening all children before they begin school, screening all individuals living within a specific geographic location for DR, and screening patients who live in a retirement community. Each of these broad types will be discussed in detail. 


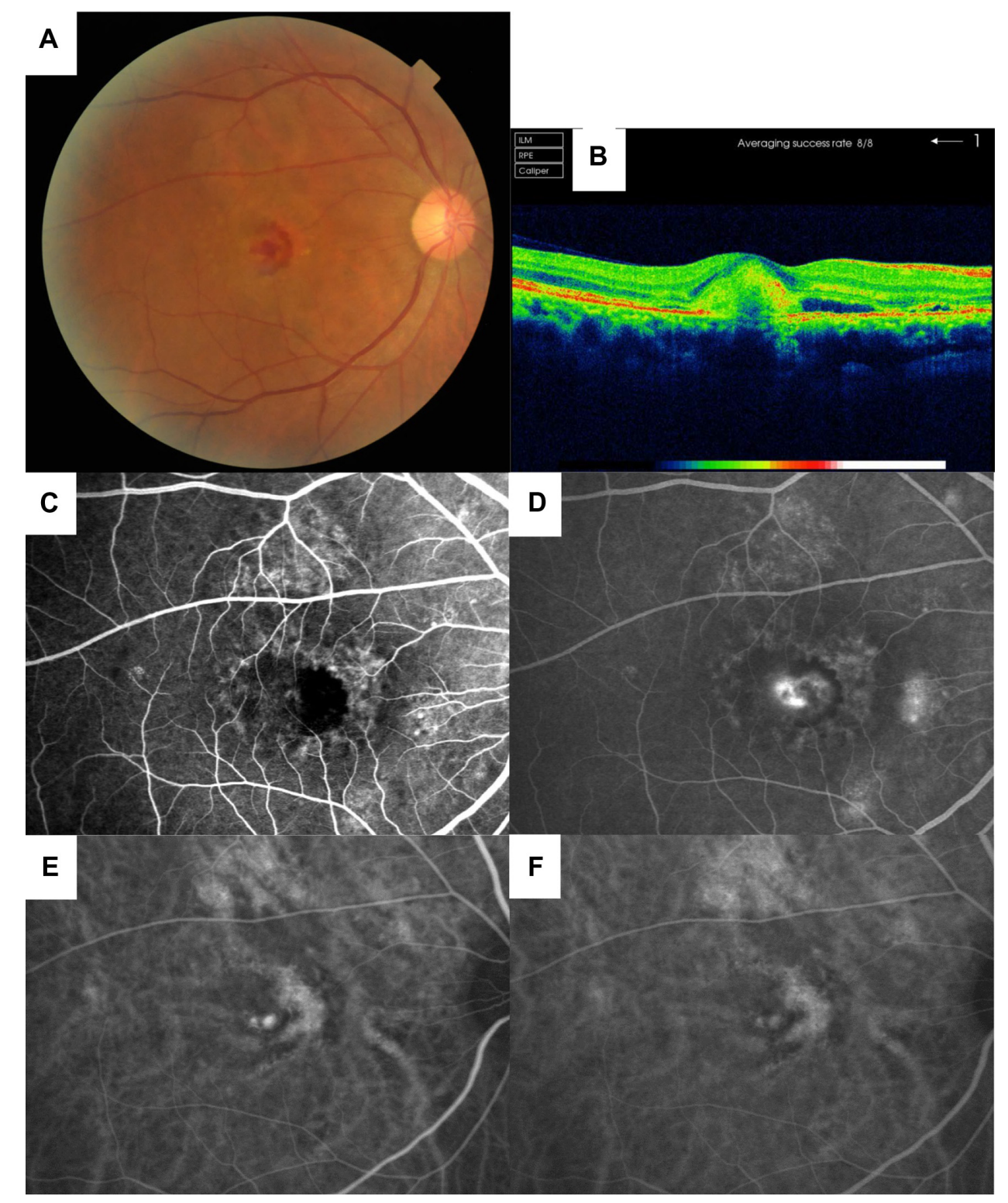

Figure 2 AMD with minimally classic CNV in AMD, shown with several imaging modalities provided by Dr Masahiro Miura, Tokyo Medical University, Tokyo, Japan.

Notes: (A) Color fundus image, showing hemorrhage associated with CNV and drusen eccentric to the fovea. (B) SD-OCT (6 mm scan) in false color, showing subfoveal CNV displacing the normal foveal layer structure, an increase in the central retinal thickness, disruption of the RPE, and several regions of fluid. (C) Arteriovenous-phase FA, showing blockage of the foveal fluorescence by blood and fluid, surrounded by several loci of capillary leakage and hyperfluorescent foci, particularly at 3 o'clock and 5 o'clock. (D) Late-phase FA, showing continued focal leakage and blockage of the underlying fluorescence by the hemorrhage. The hyperfluorescent foci surrounding the fovea also show continued leakage. (E) Early phase ICGA, showing focus of main leakage for the CNV as bright spots. In addition, the depth of the hyperfluorescent foci outside the fovea is shown to be above the choroid and associated with pigmentary changes. (F) Late-phase ICGA, with the retroillumination by the fluorescence of the choroidal vessels demonstrating the extent of fundus changes.

Abbreviations: AMD, age-related macular degeneration; CNV, choroidal neovascularization; SD-OCT, spectral domain optical coherence tomography; RPE, retinal pigment epithelium; FA, fluorescein angiography; ICGA, indocyanine green angiography.

Vision screening can also be targeted to a geographic area or socioeconomic group or through a governmental or nongovernmental agency. The goal is to distribute eye care resources efficiently, often because the demand for eye care services greatly exceeds the available resources. However, in some cases the resources are present, but the patients do not perceive the risks of sight-threatening vision loss. ${ }^{12}$ Successful models range from but are not limited to a permanent screening and patient-referral network ${ }^{13,14}$ (Figure 6) to an annual targeted campaign by Volunteer Optometric Services to Humanity (VOSH) with known referral for patients (Figure 7) to a specific campaign at a new location.

As a practical consideration for delivering eye care, the historic methodology of optometric practice may not keep pace with population aging, which is the proportional increase of older individuals in many countries. ${ }^{6}$ This leads to a corresponding increase in the prevalence of several macular diseases that have age as a risk factor or progress with age. 


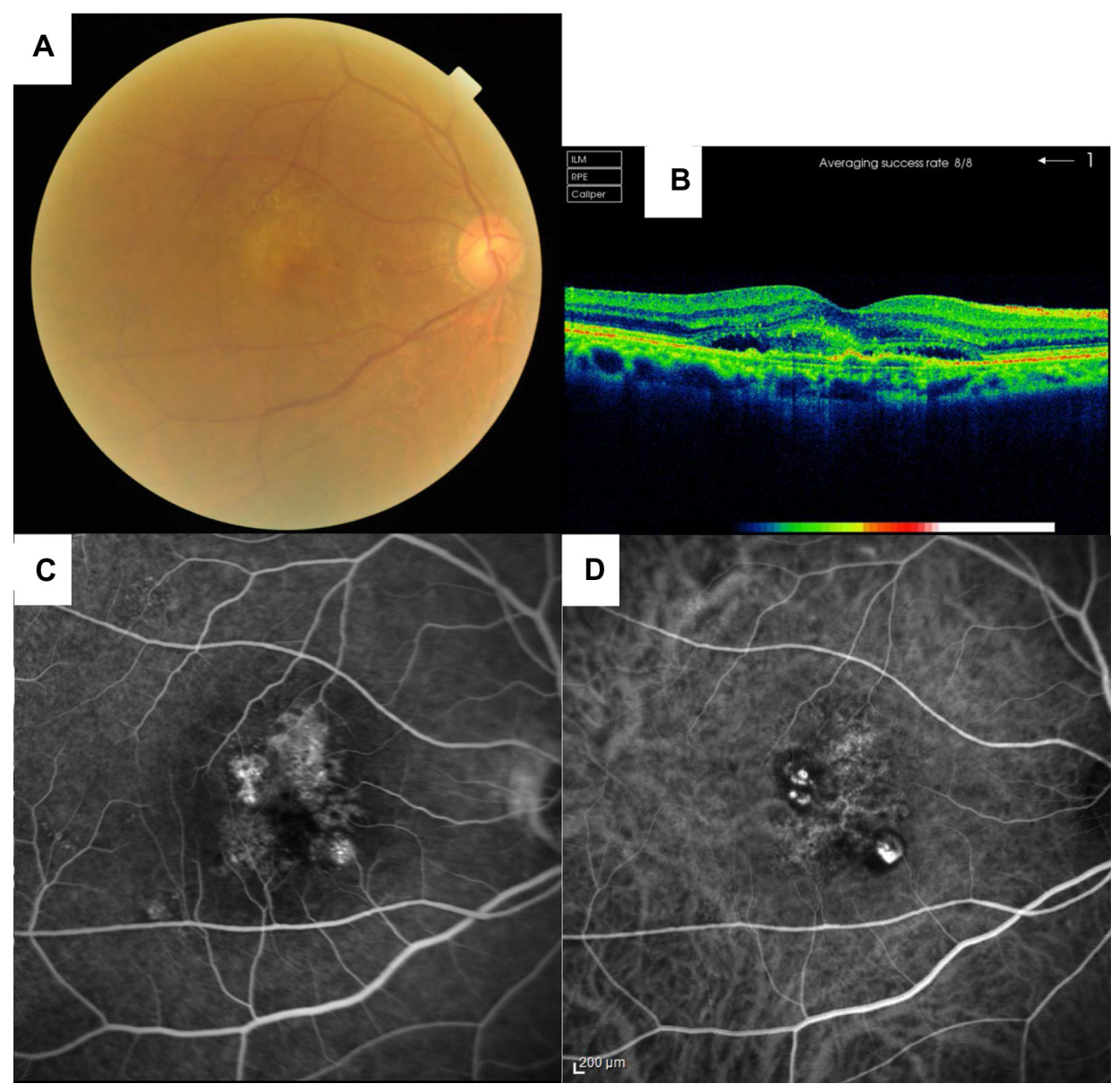

Figure 3 PCV shown with several imaging modalities provided by Dr Masahiro Miura, Tokyo Medical University, Tokyo, Japan.

Notes: (A) Color fundus image, showing some hemorrhage associated with PCV, particularly superior to the fovea. (B) SD-OCT (6 mm scan) in false color, showing subfoveally an exudative lesion displacing the normal foveal layer structure, an increase in the central retinal thickness, disruption of the RPE, several regions of fluid, and hyperreflective foci both above and below the ELM that may correspond to the many retinal vessels of the complex neovascular net characteristic of PCV. (C) Arteriovenousphase FA, showing multiple hyperfluorescent areas of vascular lesions surrounding blockage of the foveal fluorescence. (D) Early phase ICGA, showing polypoidal lesions as bright spots and a branching vascular network covering a large area of the macula.

Abbreviations: PCV, polypoidal neovascularization; SD-OCT, spectral domain optical coherence tomography; RPE, retinal pigment epithelium; ELM, external limiting membrane; FA, fluorescein angiography; ICGA, indocyanine green angiography.

Unfortunately, there are proportionally fewer eye care providers in the demographic to care for older patients.

The proportion of older individuals varies considerably by country and region. Consider the example of diabetes. Practitioners in a country with a low incidence of diabetes, which is the number of new cases of diabetes per year, could find that they have a national problem emerging because of population aging. Therefore, the prevalence of diabetes, which is the proportion of cases of diabetes in the population at a given time, may be greater than is generally appreciated. The top three countries for percentage of the population $>60$ years old are Japan, Italy, and Germany, ranging from $30 \%$ to $26.8 \%{ }^{6}$

Considering the worldwide statistics on diabetes, in some geographic locations undetected diabetes is estimated as high as $60 \%$ of cases, and values of $25 \%$ or more undetected cases are typical..$^{15}$ There are $382,000,000$ people with diabetes, and the majority are working-age. ${ }^{15}$ In addition to the social costs of diabetes, US $\$ 548,000,000,000$ is estimated for health spending worldwide for diabetes alone. ${ }^{15}$ Therefore, diabetic individuals make up an important proportion of those at risk for vision loss, which is why screening is supported in some nations.

When screening is being considered as an effective strategy, the numbers of individuals in the population must be considered along with population aging. For example, the International Diabetes Foundation estimates that the top ten countries for diabetes in individuals aged 20-79 years are the People's Republic of China, India, the US, Brazil, Russia, Mexico, Indonesia, Germany, Egypt, and Japan, ranging from 98.4 million to 8.2 million. ${ }^{16,17}$ Clearly, the first few countries in the list are known for large 


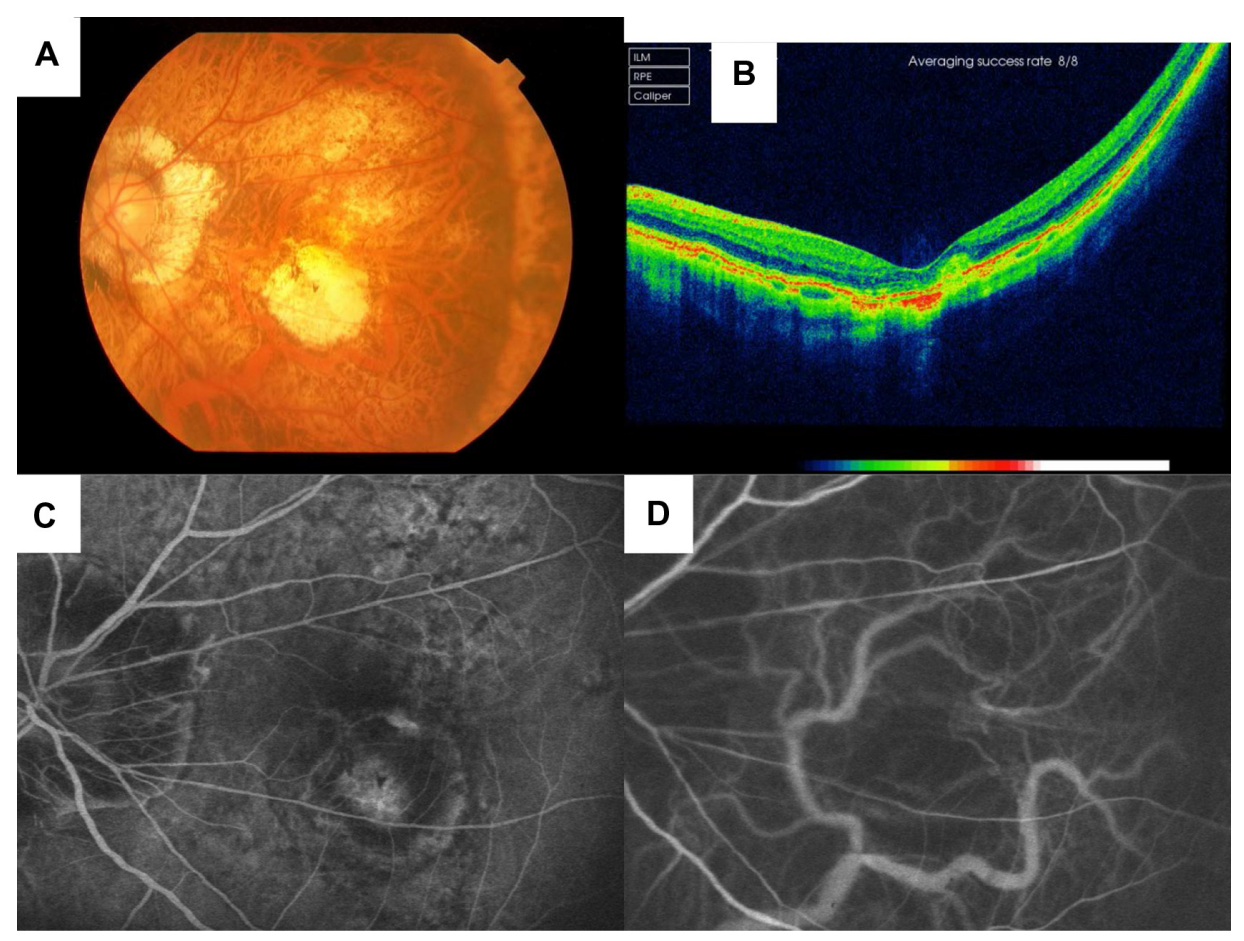

Figure 4 High myopia leading to degenerative myopia, shown with several imaging modalities provided by Dr Masahiro Miura, Tokyo Medical University, Tokyo, Japan. Notes: The left eye has fresh myopic CNV and staphyloma. (A) Color fundus image, showing choroidal vessels readily visible through RPE atrophy, and large regions of RPE atrophy in the macular and peripapillary regions. (B) SD-OCT (6 mm scan) in false color, showing subfoveal CNV slightly temporal to the fovea and displacing the normal foveal layer structure, as well as disruption of the RPE. The highly curved appearance of the scan is typical of highly myopic eyes. (C) Arteriovenous-phase FA, showing multiple hyperfluorescent areas of CNV surrounding a ring of hypofluorescence at the fovea. There are extensive breaks in the fluorescence, consistent with RPE change and breaks in Bruch's membrane in high myopia, as well as hypofluorescence associated with the peripapillary atrophy. (D) Early phase ICGA, showing extensive areas of hypofluorescence in both the foveal and peripapillary regions, particularly when compared with Figures 2E or 3D.

Abbreviations: CNV, choroidal neovascularization; RPE, retinal pigment epithelium; SD-OCT, spectral domain optical coherence tomography; FA, fluorescein angiography; ICGA, indocyanine green angiography.

populations, regardless of the incidence of diabetes. Therefore, while Japan has a much-lower incidence of diabetes than many countries, with estimates from about $7.4 \%$ to $9 \%,{ }^{15,18}$ this is overruled by the Japanese population numbering $127,353,000$ and the high proportion of individuals $>60$ years.

\section{Screening as a means to distribute access to eye care to patients unaware of the necessity of eye examination}

One of the reasons to screen is that populations at risk may not realize the high likelihood of vision loss. For DR, recommendations include an initial dilated and comprehensive eye examination by an ophthalmologist or optometrist shortly after diabetes diagnosis for type 2 diabetes and within 3-5 years after diagnosis for type $1 .{ }^{19}$ Annual reexamination is also recommended, but the follow-up interval may be increased to 2-3 years with advice in the context of the eye exam. We performed a screening study as a follow-on to our previous report on the use of hard exudates in screening for DME. ${ }^{14}$ Diabetic patients were recruited from a countyfunded clinic in Alameda County, California, USA. The research was conducted in accordance with Good Clinical Practice, the International Conference on Harmonization guidelines, the Declaration of Helsinki, and the Health Insurance Portability and Accountability guidelines. In addition, the institutional review boards of Indiana University, University of California - Berkeley, and Alameda Health approved this study, and subjects consented on approved forms. In our initial review of these screening data, more than $66 \%$ of 2,050 diabetic patients reported that their last eye exam had been conducted more than 3 years previously. These patients are considered underserved, and are $>90 \%$ minority patients, who typically lack adequate insurance for an eye examination through private optometric offices.

Similar findings came from a state-wide screening program in Connecticut, in which 568 adults were screened during a comprehensive nurse visit and 145 cases of DR found. ${ }^{20}$ Nearly $60 \%$ of the study patients were minorities, and $24 \%$ were uninsured. The recent change in health care regulations 


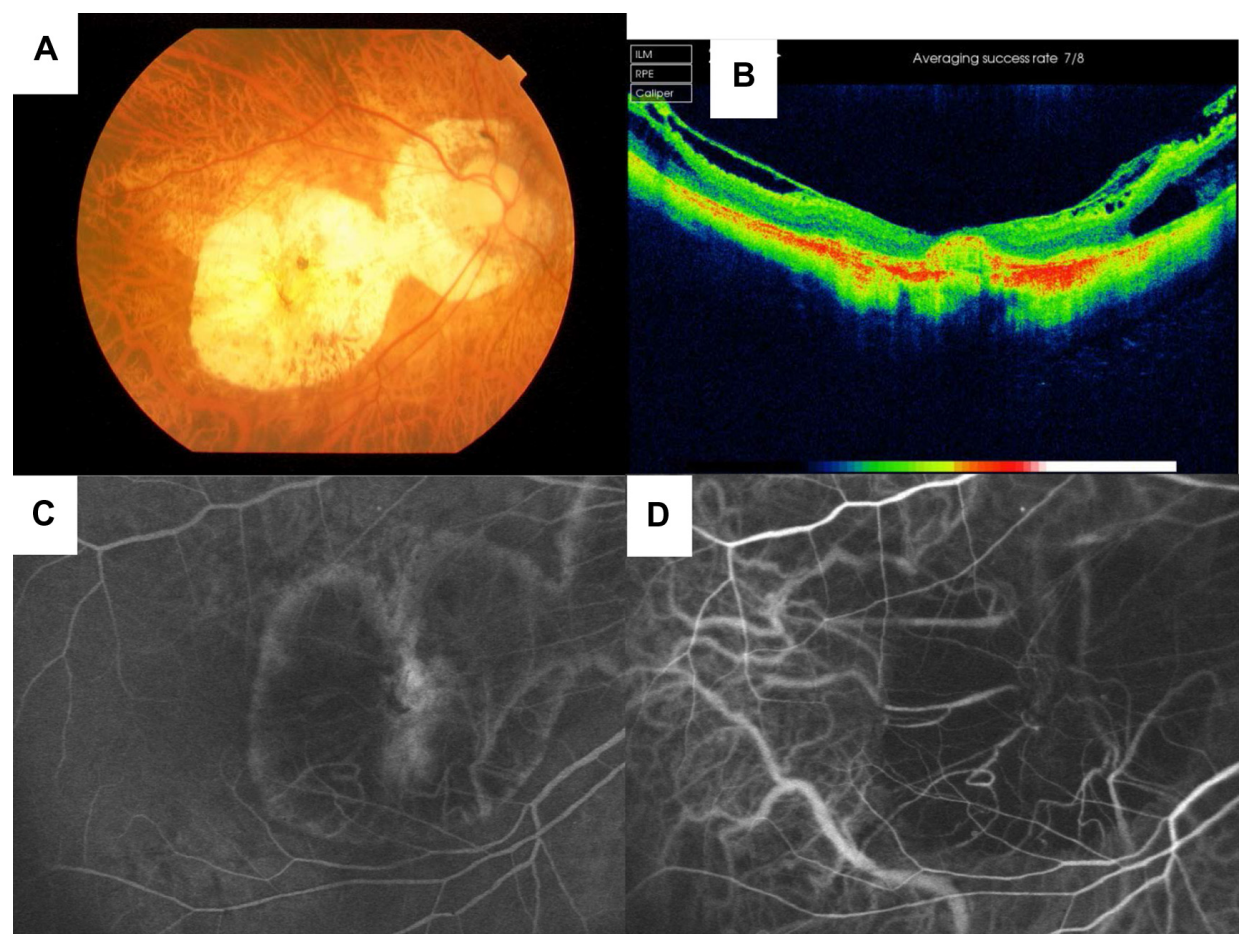

Figure 5 High myopia leading to degenerative myopia, shown with several imaging modalities provided by Dr Masahiro Miura, Tokyo Medical University, Tokyo, Japan. Notes: The right eye has myopic retinoschisis, fibrosis after myopic CNV, and staphyloma. (A) Color fundus image, showing choroidal vessels readily visible through the thinned retina, large regions of RPE atrophy in the macular and peripapillary regions, and an elongated optic nerve-head appearance related to tilt. (B) SD-OCT (6 mm scan) in false color, showing fibrosis from subfoveal CNV slightly nasal to the fovea and displacing the normal foveal layer structure, as well as disruption of the RPE. There is retinoschisis outside the foveal region, and a curved appearance of the scan. (C) Arteriovenous-phase FA, showing CNV multiple hyperfluorescent areas of CNV surrounding a ring of hypofluorescence showing extensive spread of the CNV across the macula. (D) Early phase ICGA, showing extensive areas of hypofluorescence in the central macula, corresponding to the atrophy seen in $\mathbf{A}$.

Abbreviations: CNV, choroidal neovascularization; RPE, retinal pigment epithelium; SD-OCT, spectral domain optical coherence tomography; FA, fluorescein angiography; ICGA, indocyanine green angiography.

in the US will provide the opportunity for evidence-based medicine to examine if there is an improvement in the detection of DR in a timely manner.

As individual populations do not have equal access to eye care, screening can serve to distribute resources and raise awareness of eye conditions leading to visual impairment. Using the

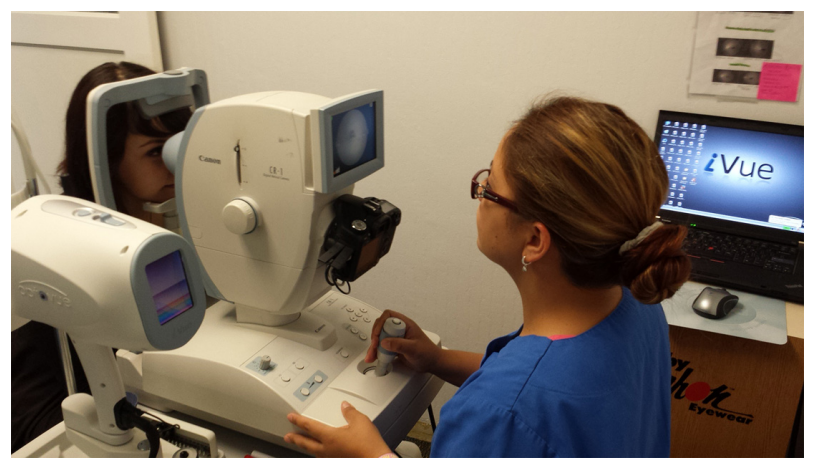

Figure 6 An EyePACS screening setting in Alameda County, CA, USA.

Notes: Typically, patients to be screened come to a site associated with a health care setting. There is a trained photographer associated with the site, with equipment habitually situated in a light-controlled setting. Internet is provided at the site for secure, web-based transfer of data to expert grading centers, usually offsite.
US as an example of a multicultural and industrialized country, the Centers for Disease Control and Prevention reports that nearly 24 million Americans have diabetes, and about a quarter (5.7 million) of them do not know that they have the disease. ${ }^{21}$ The number of people estimated to have DR in the US is over $12,000,000$ if a definition of presence of microaneuryms is used. ${ }^{22}$ For minority patients, the first diagnosis can have worsethan-average symptoms. ${ }^{23}$ The rate of diagnosed diabetes is highest among American Indians and Alaska Natives, followed by non-Hispanic blacks and Hispanics. DR is particularly high in Hispanic individuals, with a prevalence of $46.9 \%$ reported in Mexican Americans. ${ }^{24}$

Public Health England has their National Health Service Diabetic Eye Screening Programme to offer all people aged 12 years and over regular eye examinations for DR, aimed at detecting a high proportion of sight-threatening retinopathy to ensure that diabetic eye disease is treated effectively and within an appropriate time scale. Despite these resources and the fact that the UK has diabetes registries, minority patients have increased rates of sight-threatening retinopathy or maculopathy. ${ }^{25}$ Screening for DR is recommended at the time 


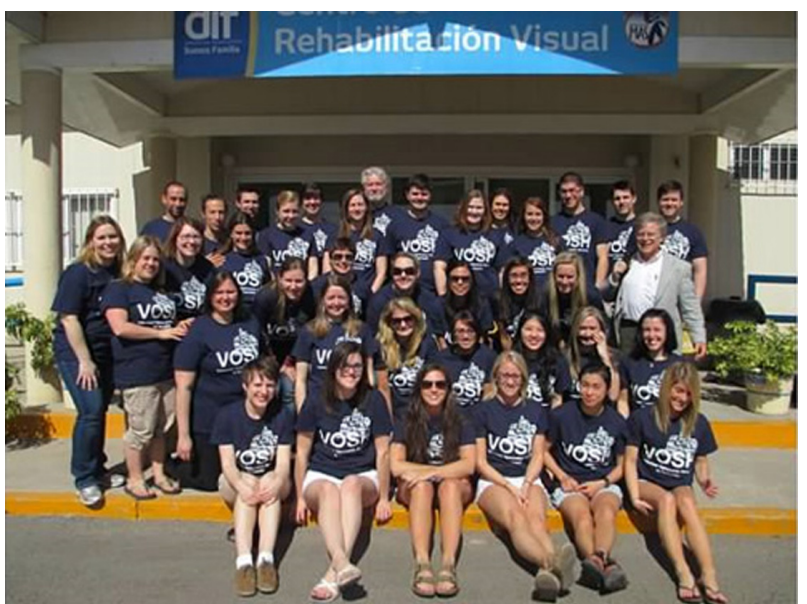

Figure $7 \mathrm{VOSH}$ volunteers with a wide range of expertise plan and carry out a screening and triage campaign ranging from 2,500-3,500 patients per year.

Notes: The campaign is conducted in collaboration with governmental agencies in the state of Guanajuato, Mexico. Patients are selected and transported for screening, according to their need and location of residence. A permanent and light-controlled building is used for crucial functions. For VOSH campaigns since the building of the permanent clinic in Silao, Guanajuato, patients can be appointed for follow-up care, including surgery at the screening location.

Abbreviation: VOSH, Volunteer Optometric Services to Humanity.

of diagnosis and annually in the UK, as is establishing strong links with primary care and diabetology services and control of blood pressure. ${ }^{26}$ Pregnant women are recommended for screening at their first prenatal checkup and again at 28 weeks if the first screening is normal. ${ }^{27}$ With dedicated diabetic eye clinics, patients without severe retinopathy and treated stable retinopathy can be seen in virtual clinics providing retinal imaging, as described herein.

\section{DR and DME, and atherosclerosis/ vascular diseases}

The mechanisms leading to DME are complex, and thus there is not just one feature that guarantees correct detection. ${ }^{28,29}$ Both neural damage and dysregulation of blood flow occur, along with the more visible signs of changes to retinal blood vessels. The Early Treatment Diabetic Retinopathy (ETDRS) classification guidelines ${ }^{30}$ have been simplified in a widely used international classification ${ }^{31}$ where the stages include no retinopathy, mild diabetic nonproliferative retinopathy (microaneurysms only), moderate diabetic nonproliferative retinopathy (more than mild but less than severe nonproliferative DR), severe nonproliferative DR (20 intraretinal hemorrhages in each of four quadrants around the optic nerve head, venous beading in two quadrants, or prominent intraretinal microvascular abnormalities in one quadrant and no signs of proliferative DR); and proliferative DR (neovascularization or vitreous/preretinal hemorrhage). Hard exudates are associated with a reduction in VA by the ETDRS. ${ }^{32}$ Hard exudates are used as a surrogate marker for DME when increased retinal thickness cannot be determined, ${ }^{14}$ although hard exudates may not yet be visible if there is no resorption of fluid. Grading is discussed in more detail herein.

\section{Color fundus photography and en face imaging methods for DR}

Color fundus photography was used to build the ETDRS scale based on seven fields of view for the severity of DR, methodology developed before digital cameras were widely used. ${ }^{31}$ Many screening methods now use digital photography, particularly nonmydriatic cameras. ${ }^{13}$ There are a large number of potential variables in different retinal imaging protocols: mydriatic versus nonmydriatic, full color versus only redfree (blue and/or green light) retinal images are acquired or graded, wide-field $\left(30^{\circ}-45^{\circ}\right.$ or more) versus ultrawide-field images $\left(100^{\circ}\right.$ or $\left.200^{\circ}\right),{ }^{33,34}$ number and location of fields of view (one, two, three, or seven different views), stereo versus monophotography, and still versus video used at times by the Joslin Vision Network (JVN). Another important variable is whether the camera requires a high level of operator skill versus an automated camera, which is thought to require less operator skill. When fields larger than about $50^{\circ}$ are used, the optical design is not based on spherical optics, and the potentially useful field of view of the periphery is subject to additional optical aberrations and distortion. Photoscreening for DR can also be performed via slit lamp, such as with a 78 or $90 \mathrm{D}$ lens. For all the photographic methods, the images can be graded by the operator, stored digitally, and forwarded to readers, or transmitted live. ${ }^{35}$

Fluorescein angiography (FA), usually an en face technique, is used to detect leakage from damaged blood-retinal barriers that are common in diabetes, such as damaged capillaries or the retinal pigment epithelium (RPE). FA requires the following: injection or ingestion of fluorescein dye that can cause an allergic or other anaphylactic reaction, bright short-wavelength light, and pupil dilation with mydriatic medications that may still not achieve a wide-enough pupil to support excellent results. ${ }^{36}$ In a recent study of 11,898 fluorescein angiograms, the frequency of nausea, vomiting, dizziness, fainting, and urticaria was low $-0.7 \%, 0.4 \%, 0.3 \%$, $0.1 \%$, and $0.2 \%$, respectively - and the sample did not include any cases of myocardial infarction or anaphylactic shock. ${ }^{37}$ Although oral fluorescein may be safer than the injection method, the expense and risks to the patient usually rule out FA for screening the macula. Indocyanine green angiography (ICGA) provides an improved view of the dark fundus with vessels in high contrast, but the ICG dye leaks less readily, 
is expensive, and still has the potential for anaphylactic reaction. ${ }^{38}$ Therefore, large-scale screening studies generally do not report angiographic results, and many epidemiological or natural history studies performed outside of clinics do not report these methods either.

Technical considerations for color methods include many practical aspects. What resolution and storage capacity are actually needed, and how can these be reduced? We and others have adopted a measure of $11 \mu \mathrm{m}$ of retina per pixel..$^{33,39,40}$ This reduces the number of pixels needed for storage, which for a $30^{\circ}$ field in three colors would be less than 3 megapixels. More pixels will not improve the image unless a wider field image is needed, while achieving high contrast in the image is important. Capturing red or green images separately, such as in the Optos (Dunfermline, UK), will increase the contrast in the image, but the two images must then be registered. Achieving uniformity of color balance is difficult over a wide field, and even more difficult over an ultrawide field. Reducing the cost and making cameras more robust and energy-efficient has been made possible by the use of lightemitting diode (LED) sources, and care still must be taken in using bright lights and particularly short wavelengths, as discussed further.

The grading of the images is performed by trained and certified graders in some screening systems, such as described herein by the JVN or EyePACS, or by computer algorithm. The frequency of screening varies, from once per year to a variable interval between screening sessions that depends upon the risk assessment of each patient. ${ }^{41,42}$ For a wellcharacterized population, the intervals can be shorter than 1 year for patients more at risk and longer for those less at risk, saving costs and the patient's time.

\section{Improvement of image contrast by scanning or confocal imaging techniques}

The anterior segment produces unwanted scattered light, which degrades the fundus images and makes the images look less sharp. One method to improve the contrast of images is to scan the light across the fundus, either point by point or line by line, and then to detect the light returning from the fundus from each point or line separately in time and synchronized with the illumination. ${ }^{36}$ This well-known scanning technology, providing the basis of such technologies as the scanning laser ophthalmoscope, has been commercialized by a number of vendors. Another optical means to increase image contrast is to use a confocal aperture, which is an opening in the optical path through which the light travels, and is positioned in a plane conjugate to the fundus, so that unwanted scattered light is blocked from other planes of focus or to the sides.

En face images using confocal and scanning technologies are available in such devices as the Spectralis (Heidelberg Engineering, Heidelberg, Germany), used alone or to guide other imaging modalities. The retinal images may be of reflected light, or fluorescence, as in the FA or ICGA images (Figures 2-5). The same scanning principle is used in the ultrawide-field Optos models, with a red line and a green line scanned sequentially and the color image built up from the combination, which maintains high color contrast. ${ }^{34,35}$ Scanning technology is used in the MAIA (OptoVue, Pisa, Italy) to improve the contrast of the retinal image during fundus perimetry, but scanning is missing from the imaging of the MP-1 (Nidek, Gamagori, Japan). ${ }^{39}$ While many of the scanning and confocal instruments have demonstrated visualization of vessel changes and cystoid macular edema via high-contrast images and scattered-light imaging, ${ }^{43-45}$ the cost is prohibitive for use with screening in some settings or for some applications. Lower-cost technology to sequentially illuminate the fundus without using expensive scanning motors has been demonstrated, using a digital light-projector method. ${ }^{40}$ For all the en face methods, the sensitivity depends upon the goal of the screening, which could range from identifying diabetic subjects who may have early signs of DR and should be more closely followed to identifying those patients who require treatment due to sight-threatening retinopathy that requires immediate referral for treatment.

Optical aberrations of the eye can be compensated sufficiently by the fact that very high-resolution en face images of the retina reveal details not visible on clinical examination. ${ }^{2,46}$ Optical aberrations increase significantly with age. ${ }^{47,48} \mathrm{~A}$ variety of instruments, known as Adaptive Optics imaging, have been developed that produce images with high contrast and high resolution. The best of these devices have resolutions of less than $2 \mu \mathrm{m}$ laterally across the retina, imaging subcellular structures of blood vessels, finding pathological changes to capillaries in mild DR, and allowing counting of cone photoreceptors. Particle motion can be computed over time, so the retinal vessels, including capillaries, are mapped without the use of contrast agents, such as fluorescein. ${ }^{2}$ While these devices may eventually be developed into macular screening devices, the cost of the instrumentation and the skill of the operator have prevented their use in screening to date. 


\section{Detection of DME and macular edema from retinal vascular damage}

Hard exudates are a sign of current or previous DME that localize the residue from serous leakage from damaged capillaries, although they may not indicate the exact location of vascular damage that is the source. DME is considered absent if there is no apparent retinal thickening or hard exudates in the posterior pole, mild if the hard exudates or edema are distant from the center of the macula, moderate if the exudates or thickening approach but do not involve the center, and severe if the exudates or thickening involve the center of the macula. Clinically significant macular edema occurs at the rank of severe, when there is any of the following: 1) thickening of the retina involving the center of the macula, 2) hard exudates at or within $500 \mu \mathrm{m}$ of the center of the macula with thickening of the adjacent retina, or 3) a zone of retinal thickening one disk area or larger, which is within one disk diameter of the center of the retina. ${ }^{46}$ As stereophotography, biomicroscopic examination, or slit-lamp examination are needed to clarify retinal thickening in many cases, the presence of hard exudates is considered a biomarker.

Proliferative retinopathy, severe nonproliferative retinopathy, and clinically significant macular edema are considered sight-threatening retinopathies for the purposes of epidemiological studies, but the damage to the retina has already occurred in some eyes when patients are classified with only mild or moderate nonproliferative retinopathy., ${ }^{2,49}$ A variety of vascular diseases negatively affect the retina, and vein occlusions also lead to macular edema. The MESA (Multi-Ethnic Study of Atherosclerosis) graded photographs from a $45^{\circ}$ nonmydriatic digital fundus camera: the prevalence of any retinopathy was $33.2 \%$ and macular edema $9.0 \% .{ }^{50}$ The prevalence of any DR and macular edema, respectively, was significantly higher in blacks and Hispanics than in whites and Chinese. ${ }^{50}$

\section{Cross-sectional imaging and volume-imaging methods for detection of DME and other macular pathology}

Improved axial resolution and contrast for detecting DME and other macular pathology is provided by OCT (Figures 1-5 and 8). This technique uses the interference pattern of light returning from the fundus and a reference to measure the optical path length of fundus structures, and reports the relative distances between borders of retinal layers that differ sufficiently in refractive index..$^{36,51,52}$ DME is typically documented by central macular thickness or central retinal thickness in micrometers, or measures of volume of a specific retina region. Modern spectral domain OCT demonstrates more layers and documents damage between and within retinal layers, compared with older techniques ${ }^{53-55}$ (Figures 1 and 8). There are numerous configurations and vendors that provide axial resolutions of about $7 \mu \mathrm{m}$ in the retina. Small cystic changes are readily observed from the individual scans.

OCT is largely performed with near-infrared light, and does not require the injection of contrast agents. Therefore, the detection and management of DME is largely performed by OCT, with FA and ICGA being used for dramatically fewer tests per year. ${ }^{56}$

The relation of retinal thickness measures to retinal health is not simple. Vitreoretinal traction can distort and thicken the retina, sometimes leading to macular edema that is unrelated to diabetes. On the other hand, retinal thinning occurs with damage to neural layers. ${ }^{57}$ The lateral resolution of OCT has been limited by the speed of data acquisition, and the need to reduce the test times and register images to correct for eye movements, rather than being limited by optical principles. The characterization of retinal vessel pathology has not been a priority, because of the lack of resolution to produce detailed en face images. In a screening study of macular pathology by use of telemedicine and OCT, community optometrists in the UK did not have to be concerned with DR lesions, since these were screened by another referral pathway. ${ }^{58}$ Recently, new methods of increasing data-acquisition speed, along with new data-analysis methods, can be used to compute particle motion through blood vessels. ${ }^{59,60}$ This OCT angiography requires no dye, but visualizes capillaries and retinal and choroidal vascular pathology.

\section{Detection of vision impairment through functional testing for DR and DME}

It has long been established that there is neural damage caused by the presence of excess glucose and glucose by-products, by failure of the inner retinal and outer retinal blood-brain barriers, and by the more readily detected damage to blood vessels. ${ }^{29}$ Therefore, abnormal cone function occurs without clinical signs of retinopathy in patients with $20 / 20 \mathrm{VA},{ }^{1}$ and decreased retinal responsivity as measured by multifocal electroretinography predicts future macular edema; ${ }^{61}$ two of the many ways to detect damage to macular function. Due to the cost and necessity of trained operators, neither of these sensitive methods has been used in screening. 


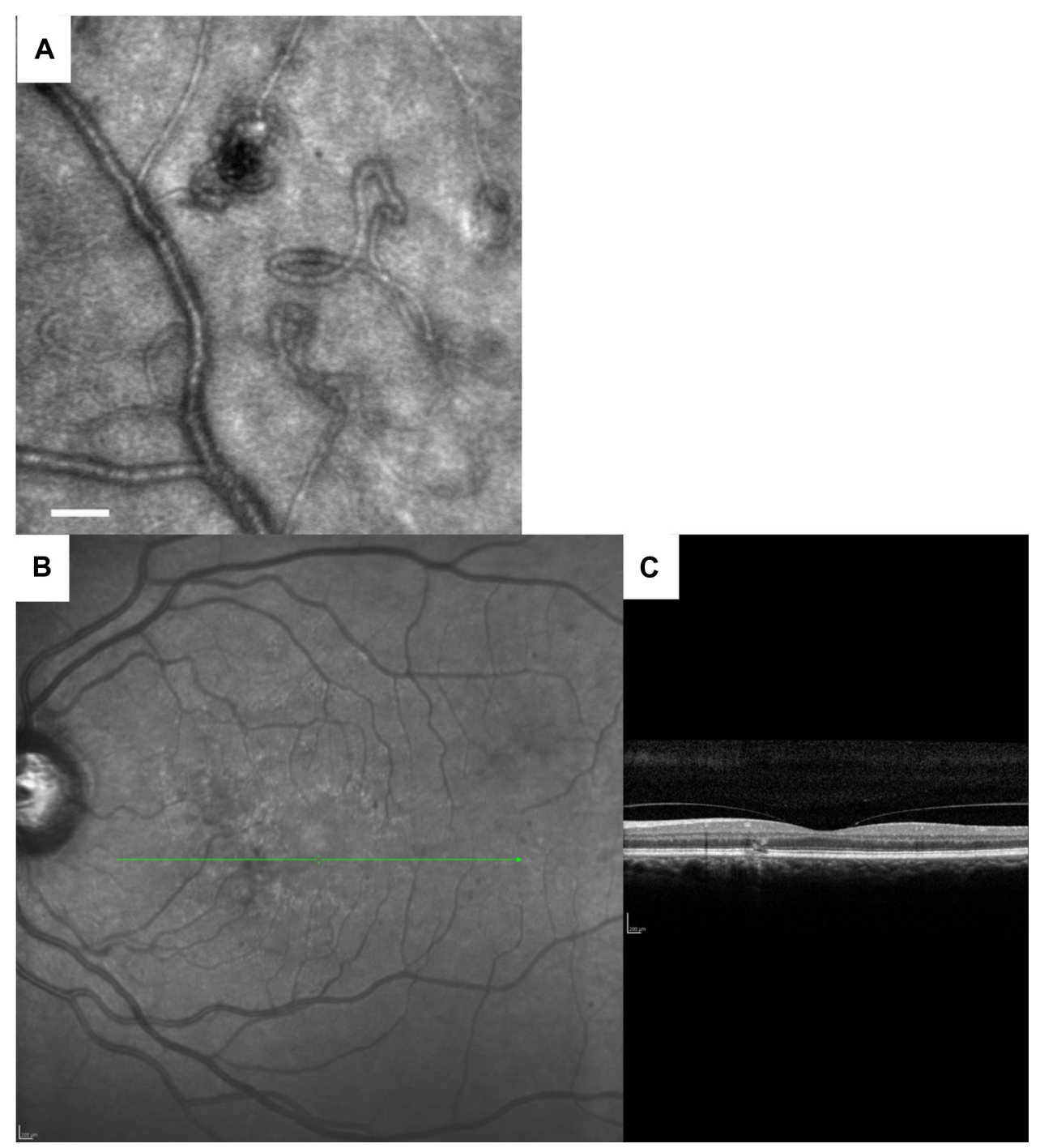

Figure 8 Retinal imaging of DR and DME more severe than can be detected by a dilated fundus examination.

Notes: (A) Capillary loops and hairpins and a microaneurysm shown with AO-SLO imaging, which are features too small to be detected with the resolution of direct or indirect ophthalmic examination. The fiducial mark is $25 \mu \mathrm{m}$ on the retina. Image provided by Dr Stephen Burns, Indiana University, Bloomington, IN, USA. (B) Long-standing DME with RPE changes too subtle to be seen with direct or indirect ophthalmic examination for several years, while readily localized with four different types of confocal and laser-scanning instruments in the laboratory. The visual symptoms were consistent with the laboratory results, and eventually the DME could be seen on examination. Here is shown the en face image from a commercial SD-OCT. (C) Corresponding cross-sectional scan from SD-OCT, showing cystic spaces and damage to the photoreceptor layer. Abbreviations: DR, diabetic retinopathy; DME, diabetic macular edema; AO-SLO, adaptive optics scanning laser ophthalmoscopy; RPE, retinal pigment epithelium; SD-OCT, spectral domain optical coherence tomography.

Recent macular function differences between diabetic patient groups and also from normal data were found with a much less expensive technology, Smith-Kettlewell Institute low luminance (SKILL) cards, which is a series of cards to test monocular high-contrast VA (white chart and black letters) and low contrast, low-luminance VA (dark chart with slightly darker letters). The SKILL score was calculated as the difference between dark-chart and light-chart acuities and was corrected for age. ${ }^{62}$ These cards are sufficiently easy to administer and have normative data over a wide range of ages. As with previous methods, the SKILL cards demonstrated vision-function changes in diabetes in the absence of clinically evident retinopathy. Reduced macular function was found in DR, while high-contrast VA remained unchanged. This type of sensitive, inexpensive, and easy-to-administer test provides a potential basis for macular screening based on function.

\section{Aging and AMD}

Age is well known to be an important risk factor for the main sight-threatening disorders that affect the macula, such as AMD, DR, glaucoma, vitreoretinal traction, and macular hole. ${ }^{63,64}$ AMD is widely recognized as the primary cause of permanent vision loss in industrialized countries and 
in many countries in which refractive error is corrected, but the incidence and prevalence varies widely with ethnic group and geographic location. ${ }^{4,64}$

While AMD is a multifactorial disease, the fundamental lesions of AMD lie beneath the retinal surface. A primary locus of damage occurs when there is local inflammation or a failure of normal lipid metabolism within the RPE, Bruch's membrane, or choroidal endothelium. ${ }^{65,66}$ Lipid and protein debris builds within Bruch's membrane, invades the RPE, and can even reach the retina when there is sufficient disruption of tissues. The material forms a barrier to normal molecule transport to support the photoreceptors. There is damage to the overlying photoreceptors, which depend upon the RPE and choroid for metabolic support, renewal of outer segments by phagocytosis, and removal of waste products and excess fluid.

The photoreceptors may become severely damaged in both structure and function, with abnormally low amounts of cone photopigment despite 20/20 VA, ${ }^{3}$ given their high metabolic demands and need for repair. However, at least some cones survive despite missing RPE ${ }^{67}$ The relatively higher reflectivity of the overlying retina compared with the RPE, along with poor anterior-segment media that become common with advancing age, make early detection and clinical management more difficult.

The international classification of the stages of severity of AMD includes both the size of the yellowish-white deposits within Bruch's membrane, drusen, and pigmentary changes to the RPE, through the exudative forms, based on color fundus photography. ${ }^{68}$ Drusen are a hallmark of AMD and aid in screening, because the high refractive index difference between the lipids and proteins in drusen compared with the surrounding retina make drusen look bright (Figure 2). Other types of deposits, such as basal laminar deposits and basal linear deposits, are too thin to be seen in a reliable manner with any method. For fundus areas within two disk diameters from the fovea in either eye, a grade of "no apparent aging changes" is given when there are no drusen and no AMD pigmentary abnormalities. Normal aging changes are graded when there are drusen $\leq 63 \mu \mathrm{m}$ and no AMD pigmentary abnormalities, but drusen $>63 \mu \mathrm{m}$ but $\leq 125 \mu \mathrm{m}$ signify early AMD. Intermediate AMD is graded for drusen $>125 \mu \mathrm{m}$ and/or any AMD pigmentary abnormalities. Late AMD is neovascular AMD and/or any geographic atrophy (GA). Exudation in AMD can take many forms: cystoid macular edema, diffuse macular edema, and pigment epithelial detachment can all be found with AMD, along with the usually extensive lesions found in retinal vascular anomalous complex or retinal angiomatous proliferation $^{69,70}$ and polypoidal neovascularization (Figure 3). These clinical entities should be considered also as late AMD, being exudative even if new vessels cannot be visualized.

The success of screening for all these categories of AMD depends on the goal of detection. At present, the treatments for early AMD are not yet proven, and therefore screening with genetics or for treatments has not been advised. ${ }^{70}$ Using modern scanning and confocal en face imaging, particularly with near-infrared light, far more and a larger extent of drusen, exudation, and related tissue damage are seen than with color fundus photography. ${ }^{71-73}$ Hyperpigmentation, which is a key variable in the international classification, is well visualized in near-infrared and red wavelengths. Adopting techniques with longer wavelengths has the potential to improve the detection of these key features, particularly in the presence of cataracts or dark fundi. Similarly, using modern OCT techniques, drusen, exudation, and other pathological changes are not only readily seen (Figure 2B), but can be automatically detected compared with the normal retina. ${ }^{74}$ While all the commercially available versions of these devices are at present costly, the very short test times and robustness through the poor media of older eyes argue for incorporating them into screening systems.

As with DR, the use of imaging modalities to obtain fluorescence measures, such as FA and ICGA, incorporates risks and requires expert operators. Fundus autofluorescence (FAF), whether stimulated by visible wavelengths or nearinfrared light, avoids the use of injected or ingested contrast agents, but depends upon intrinsic fluorophores. ${ }^{75}$ One intrinsic fluorophore is lipofuscin, which has components derived from the photopigment cycle and builds up with aging in the RPE. Patchy FAF is seen in AMD, particularly prior to choroidal neovascularization (CNV). ${ }^{76,77}$ The time and skill needed to acquire FAF images are far less than with FA or ICG, but at present the equipment is still costly and requires pupil dilation. The amount of light needed to excite the weak intrinsic fluorophores is considerable, particularly when short wavelengths are used, and has been shown to produce changes in animal models. ${ }^{78}$

Early detection for the growth of new vessels is quite different from GA, since CNV can lead rapidly to decreased vision, and damage to the retina can be lessened if the growth of the new vessel network is halted by treatment. Optometrists can play a crucial role in the ongoing eye care of patients with AMD. Management in the early stages, prompt referral, and follow-up after treatment are all important roles. In management, there is a lack of long-term success in many 
patients treated with injectables to reduce new blood-vessel growth in exudative AMD. ${ }^{79}$ The problem lies in the fact that the stimulus for new blood-vessel growth is still present, given that the retina is living but perfusion is poor. The present anti-VEGF treatments also decrease normal vessels, and not just the unwanted neovascularization. GA is now known to increase in prevalence and size in patients with repeated injections of anti-VEGF drugs to reduce neovascularization. ${ }^{80}$ Therefore, there is a need for accurate testing to minimize the potential for overtreatment, and in this case screening for new blood vessels should not have a high rate of false positives.

\section{Myopia and visual impairment in pediatric and adult populations}

High myopia and degenerative myopia are also significant risk factors of visual impairment, increasing in older individuals. ${ }^{4,63}$ Evidence for myopia as the most frequent cause of low vision when cataract is not an issue comes from widespread parts of the world, including both urban and rural areas of the People's Republic of China, ${ }^{63}$ including study participants who are largely farmers and presumably spend considerable time outdoors and not doing close work. The Netherlands has different rates of AMD being the chief cause of visual impairment, depending on refractive status, with degeneration myopia as the chief cause for highly myopic individuals. ${ }^{81}$ With treatments for reducing the progression of myopia under investigation, ${ }^{82}$ early identification of myopic changes may eventually reduce the amount of abnormally long axial length, which would then reduce the incidence of myopic degeneration.

In pediatric populations, refractive error accounts for the majority of failures to reach VA normal for a given age. Visual impairment was noted in only two of 1,118 patients $(0.2 \%)$ from ocular pathology in the Sydney Eye Study ${ }^{83}$ and six of 3,835 patients in the Multi-Ethnic Pediatric Eye Disease Study Group from Los Angeles, California. ${ }^{84}$ Therefore, the emphasis of vision screening in most pediatric populations has been to reduce amblyopia. With the recent availability of instrument-based vision screening for pediatric populations, photoscreening and handheld autorefractions become a useful, elective option for children between 6 months to 3 years of age. Older children younger than 4 years are recommended for screening. ${ }^{85}$

The polarization properties of the Henle fiber layer are used for retinal birefringence screening for strabismus and amblyopia in infants, with the relative location of each fovea mapped. ${ }^{86,87}$ Better sensitivity was found than with an autorefractor, ${ }^{87}$ offering the potential for earlier treatment.

\section{Retinopathy of prematurity}

The numbers of patients with ocular pathology and VA less than normal is substantially higher when low-birth-weight and premature infants are screened. For premature or lowbirth-weight infants, there can be pathological retinal changes when the blood vessels fail to develop normally. The rate of ROP depends upon the criterion for severity, but the incidence for any ROP was $68 \%$ among infants of $<1,251 \mathrm{~g}$. ${ }^{88}$ A review of the literature indicates that in the less severe stages of ROP, spontaneous regression of symptoms is common, but MSVI is more likely to occur in the more severe stages, particularly in untreated eyes. ${ }^{89}$ This is consistent with the potential in the early stages of ROP for downregulation over time of the growth factors that drive angiogenesis in the developing eye. Screening with retinal imaging has been used to detect ROP. The level of agreement between the grading of retinal images in infants and retinal examination is similar to the agreement between two examiners..$^{90}$ There is an increased proportion of myopia and high myopia in children who have been diagnosed with ROP, which continues through at least age 6 years, whether they were treated or not. ${ }^{91}$ The eyes of patients who had ROP can fail to develop normal foveal pits. ${ }^{92}$ Therefore, patients with low weight or who were premature may have visual impairment, and are at risk for further myopic changes. Similarly, patients with a family history of retinal degeneration are at higher risk for such conditions as retinitis pigmentosa and Stargardt's disease. However, while a carefully obtained history is useful, it cannot detect all of the wide range of genetic disorders, because a number of these are recessive or have unknown inheritance patterns. ${ }^{93}$

\section{Macular function measured with visual acuity, Amsler grid, fixation stability, and other tests}

VA, which measures visual performance for high-contrast targets, usually black letters or symbols on a white background, requires testing under strict lighting levels. This is provided by testing indoors with controlled lighting, but is also possible by blocking unwanted light from reaching the patient's head or the eye chart. A variety of electronic methods of VA measurement are now available in which the subject views a computer screen, and are reliable enough to have been incorporated into treatment trials and longitudinal studies. ${ }^{94,95}$ 
Given a primary locus of damage at the photoreceptor/ RPE level, a variety of tests have been developed to screen for damage due to AMD. Among the many potential tests, ones involving flicker have high sensitivity because of the lack of stimulus degradation by the scattered light from the anterior segment of older eyes..$^{70,96,97}$ Dark adaptation has been suggested, but does not fit the requirements for screening tests, because it needs a considerable amount of test time and adaptation of the patient to constant illumination, plus control of room illumination. ${ }^{70}$

Macular function tests that vary in spatial content include well-known measures, such as VA, Amsler grid, contrast sensitivity, SKILL cards, and others. A systematic review of the Amsler grid indicates a potential use in screening, ${ }^{98}$ particularly given its familiarity and low cost. Contrast sensitivity and SKILL cards are clearly impacted by cataracts and other media problems, but do provide functional assessments that may be valuable in understanding a patient's capabilities. ${ }^{99}$ Two popular methods of testing contrast sensitivity are the Pelli-Robson and Mars charts. ${ }^{100}$ SKILL cards are predictive of future vision loss in an aging population. ${ }^{101}$ The Berkeley Rudimentary Vision Test provides quantification of not only the range of VA covered by letter charts but also the range of VA experienced by individuals with visual impairment. ${ }^{102}$ This test uses printed cards that are readily administered with little training, along with a forced-choice response required of the patient, which makes them useful for screening. The poorer VA is probed by high-contrast gratings of increasing widths, and the poorest VA is determined by large squares, so that VAs normally given such names as "count fingers" can be quantified. This type of spatial task may be influenced by aging changes to the macula, beyond optical changes, since the density of cones decreases with age. ${ }^{103,104}$

Another type of test that is less influenced by anterior-segment media surprisingly involves spatial vision, but instead of being based on VA, the basis is Vernier acuity, which can be configured to depend minimally with age ${ }^{105}$ Vernier acuity, also known as hyperacuity, requires the judgment of whether dots or lines form a straight row or are offset, rather than requiring the detection of minimum angle of resolution (MAR). This could have advantages for both missing photoreceptor patches and distortion of photoreceptors, due to their elevation by the growth of the new vessels beneath them. This type of judgment is similar to an Amsler grid, but has only one horizontal or vertical line presented at a time. The hyperacuity technique forms the basis of the preferential hyperacuity-perimetry test, which has had promising results in home use for patients at risk for developing $\mathrm{CNV}^{106}$ and in screening studies.$^{98}$ Handheld devices, such as the iPad, iBook, Kindle, and others, have been used for acuity, contrast sensitivity, visual fields, and other tests, ${ }^{107,108}$ in addition to VA tests that are already electronic. ${ }^{94}$

Fundus perimetry, often referred to as microperimetry when the macula is the emphasis of testing, is common for AMD. ${ }^{109}$ Tasks reporting functional deficits in fixation stability, as well as loss of sensitivity, are performed with instrumentation that provides a view of the fundus while visual stimuli are presented, and have been recently reviewed. ${ }^{39} \mathrm{To}$ date, though, these devices have a cost that is too high for screening at most locations. Similarly, decreased reading speed is a functional deficit that is important in patients with AMD, and reading speed measured with the MP-1 depends upon fixation stability. ${ }^{110}$ Therefore, fixation stability, which is objective and is a far less complex task to perform and grade compared with reading, could potentially be measured instead of or along with other measures of spatial vision.

\section{Optical artifacts in screening: ocular media, pupil size, chromatic aberration, and ocular pigmentation}

There are a number of reasons for failure of screening in individual patients due to ocular artifacts. Ocular media artifacts, such as the aging lens and the development of cataracts, reduce the amount of light both reaching the retina and also returning from the retina. ${ }^{111}$ Cataractous lenses can take on a variety of patterns, and have pathological changes that differ according to the anatomical structures that are involved, ${ }^{112}$ leading to screening failures. There are increased optical aberrations, ${ }^{47,48}$ affecting both visual function measures and the retinal image observed or acquired in screening. The prevalence of cataracts increases with age, and particularly in some diseases, such as diabetes, or retinal degenerations, such as retinitis pigmentosa. The prevalence of cataracts increases with exposure to the sun. Therefore, cataracts can interfere with the testing of a large portion of individuals who most need screening, including diabetic patients, older individuals, individuals who work largely outdoors without eye protection, and individuals living in developing nations. Cataracts are often the main cause of visual impairment, and thus interfere with correct assessment of macular function through screening when the health of the retina is the object of the test. If visual performance is the goal of the screening, such as whether visual impairment is present, then measures could be influenced by the reduction of visual function in the presence of cataracts.

The effects of cataracts include blur, reduced VA, and reduced contrast sensitivity, and also a change in the 
spectral content of light reaching the retina and available in retinal imaging. There is a relative reduction of light transmission through the lens for shorter wavelengths. The short-wavelength light that provides the blue color in photographs is absorbed more than longer-wavelength light. ${ }^{111}$ Therefore, function tests requiring the patient to make judgments of fine spatial patterns or color discriminations involving blue stimuli are affected, as are tests that have short-wavelength stimulation. This has been a criticism of techniques that use short-wavelength illumination alone or in comparison with longer-wavelength light. Examples include blue-on-yellow perimetry if absolute measures of blue sensitivity are required, heterochromatic flicker techniques, and a variety of imaging methods for fluorescence, autofluorescence, ocular pigmentation, and blood flow. The impact of cataracts on macular function is difficult to predict precisely, due to the variations in refractive indices across the lens and the differing patterns of opacity and color, but a recent review discusses the interaction of cataracts and visual function testing in AMD. ${ }^{70}$

A well-known strategy to reduce the effects of cataracts on measurement is the measurement of VA through a pinhole, which reduces the area of the lens through which the light passes and thus the relative defocus of light rays reaching the retina. This will not provide improvement in testing with opaque lenses. The use of longer-wavelength visible light provides a test that can be used in more individuals, whether the test is flicker, fundus perimetry, or retinal imaging. ${ }^{39,40,96,109}$ The use of near-infrared light, too long in wavelength to be seen on examination but passing more readily through cataracts, can now be used with advanced instrumentation for retinal imaging. ${ }^{11}$

The pupil of the eye is small compared to the size of the globe, so that pupil size places severe limitations on the amount of light that can be used to illuminate the retina for visual function or viewing and the light returning when examining the retina or acquiring images. The light returning through the pupil from the retina is thought to be at best $1 \%$, but depends on wavelength, location on the fundus, ocular pigmentation, and optical methodology. ${ }^{71,113}$ This leads to variability in vision function tests and retinal imaging for similar reasons. A small pupil is an artifact that particularly impacts the older population. ${ }^{114,115}$ In room illumination, pupil size varies considerably across patients: a $2 \mathrm{~mm}$-diameter pupil is common in 70-year-old patients, but a much larger pupil is found on average in younger subjects. In dim illumination, the radius of a 70-year-old pupil can be $1 \mathrm{~mm}$ or less and the pupil for the younger eye can readily dilate to a radius of $4 \mathrm{~mm}$, which is 16 times more light entering and exiting through the pupil for the younger eye. This is more than $1 \log$ unit less light, impacting any function test that requires a specific level of light. For relatively dim illumination, a visual function test that is mainly cone stimulation for the patient with the larger pupil would have the potential for rod involvement for the patient with the smaller pupil. Although the contrast would remain the same for the large pupil and small pupil, the overall adaptation level is dramatically different, and could lead to differences in test results.

A time-honored method for reducing the unwanted effects of small or variable pupil are to use an artificial pupil the size of the smallest pupil expected, which is simple but is an inefficient use of light and can result in field-of-view restrictions due to vignetting. The artificial pupil can serve as a pinhole, in which case the effects of optical defocus are reduced. Another method is to use Maxwellian-view stimulation to reduce the potential effects of pupil size and variability across the human lens. The optical arrangement in the Maxwellian view usually uniformly illuminates a plane in the pupil that contains an optical artificial pupil, which is then optically imaged in the plane of the natural pupil. The exit pupil of the optical system is an image of the effective light source, which is usually adjusted to be entirely within the patient's natural pupil. Results in spatial tests are similar to those from artificial pupils without the extra optics, but the problems of vignetting are reduced, although defocus can still play a role in test results. ${ }^{116}$

For imaging, the light level with a small pupil may be too low to provide adequate retinal images. Many instruments have a small pupil setting, which increases the level of illumination or the gain of the detector so that an image can be captured. However, there is still the issue of variability for overall brightness and image quality among patients with different pupil sizes. The use of screening devices that are truly nonmydriatic, meaning having a small entrance pupil and not requiring dilating drops, is often emphasized in fundus cameras and other imaging instruments. The safety for pupil dilation must be readily assessed in a screening situation. In the presence of trained eye care providers or a population at low risk for angle closure, the benefits of dilation may outweigh the risks. However, the risk of dilation for screening are increased if the sterility of the eyedrops cannot be guaranteed or there is an anterior-segment lesion that would provide a pathway into the globe for pathogens present on the eye or adnexa. For some patients, such as those with shallow angles, who require medications for glaucoma, or are pregnant or nursing, the overall safety is unknown. 
The amount and duration of pupil constriction is influenced by the wavelength and overall energy in the light stimulation to the retina. Melanopsin-containing ganglion cells, known as intrinsically photosensitive retinal ganglion cells, are now known to contribute significantly to the pupillary light reflex. ${ }^{117-120}$ The absorption spectrum peaks in the short-wavelength region of the spectrum, ie, where lights appear blue, and is broad and overlaps the spectra for rods and cones. There is a sustained, poststimulus constriction that is driven largely by intrinsically photosensitive retinal ganglion cell absorption and action. A light flash containing short wavelengths leads to pupil constriction down to $3 \mathrm{~mm}$ that lasts longer than 45 seconds if sufficiently bright or long enough. The pupil constriction is greater for a blue flash than for a red flash with a similar number of quanta/second, as well as lasting longer.

There are large individual differences in fundus pigmentation, both across an individual's retina and among individuals. ${ }^{71,113}$ For the human fundus, the primary absorbers outside the fovea are melanin and blood. Melanin increases in absorption with decreasing wavelength throughout the visible spectrum. The contrast in retinal screening images is largely obtained by contrast of the absorption of the retinal vessels compared with the adjacent retina. The absorption spectra of blood components varies with wavelength, absorbing overall more in shorter wavelengths than in the near-infrared portion of the spectrum, but with both increases and decreases as wavelength decreases and differences due to oxygenated and deoxygenated hemoglobin. In darkly pigmented eyes, such as those found in minority patients in the US and many developing countries, dark irises are common, and this is accompanied by dark choroidal pigmentation. In some eyes, there is 100 times more light returned at longer wavelengths than shorter ones. The light returning from the choroid retroilluminates the retina and contributes to the contrast of the fundus seen on exam or with retinal images. When there is significant absorption of light by melanin, the contrast between the blood vessels and the fundus is reduced, particularly at short wavelengths.

The largest differences in absorption across wavelengths are often in the fovea, which is a particularly important region for screening. ${ }^{71,113,121}$ The fovea has absorption due to macular pigments, lutein, and zeaxanthin. ${ }^{122}$ The amount of absorption due to macular pigment and melanin varies greatly with wavelength and eccentricity from the fovea, with more than $1 \mathrm{log}$ among individuals. ${ }^{71,123}$ The spatial distribution of absorption can change with age, with the central foveal region having less absorption, which is consistent with changes in foveal morphology and relatively fewer foveal cones being present in the older eyes. ${ }^{121}$ Therefore, for short-wavelength imaging, macular pigment not only blocks the view of the fundus in the fovea more for some patients than others but also blocks the view in a different pattern across the fundus.

Chromatic aberration is well known to the optometrist, when light that appears red is focused more deeply in the eye compared with light that appears green. The size of the blur circle for longer wavelengths is larger than for shorter wavelengths when the shorter wavelengths are in good focus on the retina. Chromatic aberration has effects in both axial and lateral directions. The amount differs considerably among individuals, with a $2.5 \mathrm{D}$ difference not uncommon between short wavelengths and long ones in the visible portion of the spectrum ${ }^{124-127}$ and the near-infrared portion of the spectrum. ${ }^{128,129}$ The effects of lateral chromatic aberration increase with increasing eccentricity or field size. Near the fovea, the failure in alignment of blue and yellow stimuli may be so small that there is little practical effect, but at $40^{\circ}$ from the fovea, the alignment differences can be $15 \mu \mathrm{m} .{ }^{130}$ When considering any wide-field test, whether visual function or retinal imaging, chromatic aberration must be taken into account. For instance, for ultrawide fields, the displacement laterally is so large that it can be more than a pixel at the edge of the field if the full visible spectrum is used. Based on human data, achromatizing lenses can be built to overcome the average chromatic aberration of the human eye for both visible wavelength light and extended into the near infrared for modern instrumentation. There are still individual differences, and most of these designs have not been aimed at use in wide-field or ultrawide-field applications.

\section{Light control and light safety}

Light control and light safety are key requirements of screening methods. Presentation of visual stimuli must be performed in the appropriate lighting conditions to achieve results that are comparable to normative data. Large individual differences in tests as simple as VA or contrast sensitivity occur due to light level, and this interacts with refractive error and age, ${ }^{101,131,132}$ with older subjects and myopes often not reaching peak visual performance in dim conditions. Similarly, patients who are exposed to bright lights or have recently been exposed to bright lights without adequate time to adapt to the lighting specified for a specific test may perform poorly. Beyond neural adaptation, ${ }^{133-135}$ the photopigments in rods and cones may have been bleached by the exposure to bright lights in aging, AMD, several retinal degenerations, and retinal conditions that may be undetected, such as central 
serous chorioretinopathy, and require significant time for photopigment to be regenerated. ${ }^{3,133,136-138}$ For functional impairment, though, dim lighting, low contrast, optical blur, or exposure to bright lights reveal performance deficits that may be present for individuals in daily conditions and with their habitual refractive status. Dim-lighting conditions are effectively even dimmer when subjects have small pupils due to aging or previous exposure to bright lights.

Light-safety standards have been altered since the introduction of many ophthalmic examination devices, which may not yet have been retired from service. There are many proposed mechanisms of how light damages the retina. ${ }^{78,139,140}$ The short-wavelength light used for FA and autofluorescence can be bright enough to lead to retinal damage, and at times also color or red-free fundus photography, if not constrained in light level and exposure duration. The availability of bright lights in the short-wavelength region has become possible with blue and white light LEDs. A typical peak maximum for the blue emission in LEDs is $470 \mathrm{~nm}$ or shorter. This is shorter than is needed for FA or autofluorescence. The apparent color of fundus features on direct or indirect retinal exam depends upon the light source of the instrument and ocular pigmentation. There is broadband absorption of all of the absorbers in the human ocular fundus, ${ }^{71,113}$ and very short-wavelength illumination is neither necessary nor as safe as using somewhat longer wavelengths. In addition, due to the broadband spectra of the absorbers in the fundus, only a few select wavelengths are needed to accurately measure specific molecular content, so long as fundus pigmentation is taken into account. Consequently, the simplification of retinal imaging-wavelength protocols, careful light calibration, and shifting when possible to longer-wavelength light can lead to less light exposure and therefore more safety.

\section{Resolution}

The optics of the human eye result in limits on the resolution of the image formation on the retina. ${ }^{141}$ This limitation affects the crispness and clarity of the image that a patient can see for macular function testing, and also the resolution of a retinal image. The optical resolution is generally better nearer the fovea and decreases with increasing eccentricity. The optical resolution depends upon the quality of the anterior-segment optics, including not only cornea, lens, and vitreous clarity but also the evenness of the tear film. The acquisition and storage of imaging data, unless they are acquired with the use of adaptive optics or other methods to achieve wave-front aberration does not require high pixel densities, with a lateral resolution of about $11 \mu \mathrm{m}$ on the retina being adequate for screening purposes. In the axial direction, spectral domain OCT devices produce such scans as those shown in Figures $1-5$, having about $7 \mu \mathrm{m}$ per pixel. As technology advances, there may be a clinical need for the higher-resolution devices, but cost-effectiveness remains a goal of screening, particularly when the goal is the accuracy of referral of patients to a center of expertise.

\section{Who does the screening?}

When telecommunications alleviate the issue of distance between the patients and referral eye care providers, expert graders, or diagnosticians, this method of care delivery is known as telemedicine, and its history and some of the strategies have been recently reviewed. ${ }^{13} \mathrm{~A}$ wider range of activities may be present in teleophthalmology, including not only the store-and-forward method of acquiring images and other data and sending for analysis but also hybrid examination of patients using imaging or voice feeds and consultations during examinations. ${ }^{142}$ Technology ranges from high-quality cameras that may be based in permanent locations to handheld devices that can include cell phone technology. ${ }^{143-147}$ Cell phone-based cameras have the potential to be safely used with respect to light levels, ${ }^{148}$ but do not readily produce high-quality images that are necessary in screening, for reasons discussed herein.

Optometrists can have a variety of positions within these systems. Governmental and educational institutions, as well as nongovernmental organizations, such as the Lions Club, all play important roles in screening to face the enormous challenge of reducing visual impairment. Screening may be accomplished via individual effort. Screening may be performed by such programs as EyePACS (Figure 6), by building up a network of equipped sites in primary care practices or eye care sites, in cooperation with a variety of entities, such as county clinics and health care providers.

EyePACS uses store-and-forward electronic consult technology: digital images are taken in one setting (such as a clinic) and sent electronically to a provider in another location for interpretation. ${ }^{13}$ EyePACS is a clinically validated, low-cost, web-based system designed for DR screening in community health clinics. The EyePACS system allows clinics to capture and upload digital images of a patient's retina to the secure EyePACS website for interpretation by a trained clinician in a remote location. This distributed network allows the system to link primary care providers with eye care providers regardless of their physical location. Digital retinal photography coupled with remote assessment of DR through telemedicine is an accurate and cost-effective way to increase 
patient compliance with the annual screening by moving the retinal evaluation to a primary care setting. The EyePACS panel of certified, credentialed, and licensed ophthalmologists and optometrists has provided over 250,000 consults in over 360 clinics to date. The cost of retinal screening to generate referrals for patients with DR is substantially lower than individual office visits per patient: $\$ 49.95$ versus $\$ 77.80 .{ }^{149}$

In the US, another large screening network is the JVN, which is linked with a hospital and provides validated imageacquisition methodology and certified graders of photographs. ${ }^{150}$ Retinal image data are combined with evaluations that also include medical and care history to identify risk factors that influence eye-disease onset and progression and care management, including blood pressure and blood glucose measurements, such as with glycated hemoglobin. Typically, nonmydriatic images of the retinas are acquired in a physician's, endocrinologist's, or ophthalmologist's office, then transmitted securely to the Joslin Reading and Evaluation Center. The Joslin team also reports ocular pathologies other than DR. There are two important components other than screening, which include 1) evaluation and care summaries that are returned to the ophthalmologist or primary care physician within 2 business days and 2) educational material that may also be presented during the imaging process to help patients understand how diabetes management affects vision. This vision-screening service is often performed in combination with a governmental agency, such as the US Veterans Administration or US Indian Health Service, in over 70 sites and 20 states.

Screening for DR is also addressed by mobile units with onboard equipment. In a recent study from a specific geographic location in Finland, the eye care-treatment providers in each district worked closely with a mobile screening unit, leading to marked reductions in the incidence of visual impairment due to DR. ${ }^{151}$ There was also high reliability in grading of the 14,866 photographs that made up the study.

Volunteer organizations have long played a role in vision screenings, such as VOSH ${ }^{152}$ (Figure 7). In the 2013 annual campaign to serve Guanajuato, Mexico, approximately 2,500 patients were screened. During this campaign, a team of 50, including optometrists and faculty, 32 optometry students, and employees of the clinic in Silao, Guanajuato dispensed around 1,700 pairs of glasses, and referred over 350 patients for surgery. This type of campaign is planned in close association with the state, so that patient selection, recruitment and transportation from several villages, as well as follow-up care, are provided. Screening this number of patients requires 5,000-10,000 $\mathrm{ft}^{2}\left(929 \mathrm{~m}^{2}\right)$ of light-controlled space for exams and testing, plus an additional 10,000 $\mathrm{ft}^{2}$ for the triage, waiting, and other functions, which range from tent space to a permanent structure. With supervision by residents, alumni, and faculty, patients are rotated through stations of preliminary workup by the beginning students, direct and indirect ophthalmoscopy by the intermediate students and under supervision by an optometrist, and intraocular pressure (IOP) and ocular disease station led by third-year students and residents. Dispensary activities are undertaken by all students. A variety of conditions are discovered via screening: pterygium, pinguecula, keratoconus, dermoid cysts, corneal edema, skin carcinomas and melanomas, corneal ulcers, posterior subcapsular and nuclear sclerosis cataracts, congenital cataracts, asteroid hyalosis, DR, glaucomas, pseudoexfoliation syndrome, degenerative myopias, staphylomas, retinitis pigmentosa, strabismus and amblyopia, and nystagmus.

The World Health Organization describes several achievements in eye care by individual nations, including that since 1995 India has made funds available for eye care-service provision for the poorest at the district level. ${ }^{6}$ Despite the large number of individuals with diabetes in India $-65,100,000^{15}$ - there is not a nationwide screening program in India. ${ }^{153}$ India has several distinct examples of screening embedded into comprehensive eye care that serve specific geographic regions.

One example of a complete eye care system in which the screening is tightly linked with the provision of care, is the LV Prasad Eye Institute pyramidal model of eye careservice delivery. ${ }^{154}$ This model is hierarchical, in which there are "vision health guardians" from the community who are trained to create community awareness, conduct school and community screenings, distribute spectacles, screen for diabetes and hypertension, and work in coordination with other cadres of community health workers, and serve a specific population of 5,000. The next tier is the vision center, which is a primary care-service delivery unit for a population of 50,000, with vision technicians trained for a year post-high school in refraction, recognition, and referral. The next tier is the secondary care-level hospital, where a team of eye care personnel provide comprehensive eye care examinations, and diagnosis and treatment of all eye conditions. The top two tiers include a tertiary center to serve 5,000,000 people, and a center of excellence to serve 50,000,000 people, providing tertiary care, training, eye banking, low-vision rehabilitation, and research.

The Aravind Medical Research Foundation is a World Health Organization Collaborating Center for Prevention of Blindness. The Aravind screening activities include a 
wide range of activities, with large-scale publications using examination by trained eye care specialists rather than largely store-and-forward activities of photographic screening that were expensive at study onset. ${ }^{155,156}$ However, an inexpensive smartphone with a 78 or 90 D lens, mounted on a slit lamp, has been described to transmit a fundus image to an expert center. To serve a geographical region, specific camps have been set up to screen high-risk individuals, ${ }^{155}$ with examinations given onsite. The yield of patients with DR by this method was high $-20.4 \%$ - even though these patients largely knew that they were diabetic. Although treatment was provided at the base hospital, less than a quarter of the subjects with moderate-to-severe nonproliferative retinopathy or proliferative retinopathy presented for the follow-up examination within 2 months. Screening was viewed as a short-term strategy to increase awareness, with the focus on improving patient flow to eye care centers for sustained coverage.

The prevalence of specific conditions has led to the decision to screen the general population in some countries. As described earlier, diabetes is prevalent in the population in many geographic areas. For example, the goal of the DR-screening program of Public Health England is to offer all people aged 12 years and over regular eye examinations for DR, including minority individuals. ${ }^{25}$ This can be considered a closed-loop system, in which feedback for improvement at reaching the population and assessing accuracy can be computed. Similarly, in the Aravind screening camps, the data and potential treatment can be closely associated, allowing for the initial assessment to be evaluated by the eye care providers who are responsible for treatment. ${ }^{155,156}$ This method and the head-to-head comparison with methods that are considered the standard provides the potential to assess the accuracy of screening results. For instance, a specific nonmydriatic method does not work acceptably in a population with dark fundi and possible effects of exposure to the sun, but this might not be the case for other nonmydriatic methods. ${ }^{153}$

Throughout this review, there has been an emphasis on clarifying the goal of screening, and how this affects the interpretation of the results. For the example of DR, screening programs must be both accurate and reliable with high sensitivity (the proportion of subjects with the disease who have a positive diagnostic test) and specificity (the proportion of subjects without the disease who have a negative test) in detecting the main causes of vision loss in diabetes. ${ }^{157}$ As described earlier, these causes are clinically significant macular edema and severe nonproliferative or proliferative DR. However, published studies report a variety of findings, with the criteria varying between assessing microaneurysm counts, detecting patients with any DR, grading of DR, or categorizing referable DR or sight-threatening DR.$^{58}$ Reliability is often not reported. ${ }^{158}$ The British Diabetic Association has recommended sensitivity and specificity rates of $80 \% .{ }^{159}$ Clearly, screening results in dark fundi with ungradable images $>30 \%$ and sensitivity and specificity not exceeding $63 \%$ and $69 \%$, respectively, indicate a method that is not optimized for that population. ${ }^{153}$

The risk of the screening test per se is small in DR screening when nonmydriatic methods are used. The risk of failure to identify cases at risk, ie, false negatives, is much higher, given that early treatment is effective for both DR and DME. ${ }^{157}$ The risk of incorrectly identifying normal cases as having DR or DME, ie, false positives, leads to overreferral. ${ }^{14}$ While false positives of DR or DME lead to an inefficient use of resources, a patient's having a dilated examination and more careful assessment that is given by screening is of low risk to the patient unless they are critically ill. The dilated examination and extra emphasis on health care are potentially of some benefit for a diabetic patient. The same argument cannot be made for false positives for ROP in infants with very precarious health. The consequences of false negatives, ie, of missing neovascularization, can likewise be severe. However, the false positives are also extremely important, because a full ophthalmic examination of these infants has real risks, and the prevalence of retinopathy that does not regress is relatively low.

\section{The many roles of an optometrist}

The role of the optometrist can take many forms, in three broad categories. First, the optometrist and staff can provide screening that leads to a comprehensive examination or referral for a specific issue. One option is screening patients at a satellite location or specific location where high-risk patients are, followed by a referral to the office for a more comprehensive examination or treatment. The referral location may be the optometrist's own practice or on-site station in a screening campaign. The referral is usually to a location with a higher level of equipment and sufficient time to complete the more thorough examination. One type of screening is a focused screening of patients living in a retirement community, who may have mobility issues or lack transportation, or patients having health issues that lead to risks in attending even routine appointments.

A second type of screening is a screening campaign to a specific geographic location, such as a VOSH trip, with 
specific team members assigned to triage patients to stations that distribute spectacles while other stations provide a retinal examination. It has been argued that he distribution of spectacles interferes with the financial support of local solutions for refractive correction, but efficient spectacle distribution can draw in screening patients, ${ }^{160}$ who can then have an eye care professional knowledgeably explain that their visual impairment is due to DR.

A third type is a screening network, in which a larger number of sites for screening or referral use common resources or methods. The network may be organized as a series of nodes connected to one or more central reading or treatment centers, or it may be organized in a hierarchical manner.

In these types of screening, the roles of the optometrist are similar, in that there is a screening component outside the comprehensive-examination mode of practice in offices or clinics specialized for eye care. The referral for the patient does not necessarily involve any personnel from a specific practice. The optometrist's role might be as the screener or the eye care provider who receives the referral. Insurance and other financial drivers have been in a state of flux in the US. From the patient's perspective, when an issue has been identified through screening, then the next step is obtaining the referral eye examination. This works best when there is a systematic and rapid route to the appointment process for the comprehensive examination and if necessary treatment.

Electronic transfer of images and other data is an efficient method of communicating results, ie, via telemedicine, as long as the screening test is of high quality and does not need repeating.

In all the populations screened, the role of the optometrist also includes combining imaging or functional data with a careful history. In some cases, the history is sufficient to indicate risk and the need for closer following of a particular patient. In diabetes, the risk factors of blood glucose, duration, and blood pressure determine the length of time needed between exams. ${ }^{40}$ Several important risk factors are strongly and consistently associated with late AMD, which are readily assessed through discussions with patients and do not require detailed medical history or laboratory tests: age, current smoking, cataract surgery, and potentially family history are strongly and consistently associated with late AMD. ${ }^{161}$ Other significant factors with a lower strength of association (risk estimates generally 1.5 or less) are body mass index, hypertension, a history of cardiovascular disease, and plasma fibrinogen. All of these factors are associated with cardiovascular disease, and are also likely to be measured and monitored in the primary care setting. For pediatric patients, low birth weight or premature birth, along with family history of retinal blastoma, place patients into very different risk categories for visual impairment. Drug toxicity is also important in the complete history. Therefore, the optometrist's main role when screening systems are used is to determine the most cost-efficient strategy to carry out excellent patient care.

For optometrists setting up a comprehensive screening unit, the devices and support systems can be scaled to match the numbers of patients and the resources available. As discussed earlier, the history and general health tests and demographics are an important part of assessing the risk of sight-threatening disease. This information can be obtained on site or from electronic health records. The assessment of visual function is readily performed in an optometrist's office or a screening site set up by optometrists, with testing ranging from a traditional VA chart with $\log$ MAR or electronically specialized tests that allow testing of patients with low vision. Types of electronic VA and Vernier testing devices are available commercially. Several types of electronically administered vision tests are available commercially, including the ForeseeHome device. The Amsler grid may lack sensitivity, but is readily available in paper form and online.

Fixation stability is available with fundus-perimetry devices, with at least two being actively marketed along with legacy devices and laboratory devices, most of which are expensive. The methodology to support fixation-stability assessment could be readily introduced into most retinal imaging devices, although these devices are expensive. Other tests of visual function, particularly those that probe the vision at dim-light levels or reduced contrasts, are available in both very affordable chart as well as electronic forms.

Photoscreening can be introduced by a wide variety of cameras, with en face imaging devices that produce color images usually less expensive than devices to measure retinal thickness, such as OCT. Numerous vendors have retinal imagers from flash or LED stimulation, and fewer vendors have introduced the more expensive laser-scanning retinal imagers that provide crisper images, particularly for autofluorescence or longer-wavelength imaging. Ultrawidefield retinal imagers are available from a limited number of vendors, and newer models are under development, but have significant cost considerations. In summary, the screening options are varied, and present the opportunity for new models of patient flow to optimize the cost-effectiveness of providing eye care. 


\section{Acknowledgments}

We thank the following colleagues for suggestions and images: Drs Mark Bullimore, Stephen Burns, Jorge Cuadros, Douglas Horner, Masahiro Miura, Tawna Roberts, Vidhyapriya Sreenivasan, and William Swanson, as well as Ms Anna Sorenson. Drs Jorge Cuadros, Taras Litvin, and Glen Ozawa, and Mr Matthew Muller provided the data on underserved patients in Alameda County, CA, which was organized by Dr Karthikeyan Baskaran. This research was supported by EY007624, EY018772, and EY020017. The content is solely the responsibility of the authors and does not necessarily represent the official views of the US National Institutes of Health.

\section{Disclosure}

AEE is an owner and inventor on a patent licensed by Aeon Imaging. The authors report no other conflicts of interest in this work. The authors take responsibility for the integrity of the data and accuracy of the data analysis.

\section{References}

1. Elsner AE, Burns SA, Lobes LA Jr, Doft BH. Cone photopigment bleaching abnormalities in diabetes. Invest Ophthalmol Vis Sci. 1987;28(4):718-724.

2. Burns SA, Elsner AE, Chui TY, et al. In vivo adaptive optics microvascular imaging in diabetic patients without clinically severe diabetic retinopathy. Biomed Opt Express. 2014;5(3):961-974.

3. Elsner AE, Burns SA, Weiter JJ. Cone photopigment in older subjects: decreased optical density in early age-related macular degeneration. J Opt Soc Am A Opt Image Sci Vis. 2002;19(1):215-222.

4. Stevens GA, White RA, Flaxman SR, et al. Global prevalence of vision impairment and blindness : magnitude and temporal trends, 1990-2010. Ophthalmology. 2013;120(12):2377-2384.

5. Bailey IL, Lovie-Kitchin JE. Visual acuity testing. From the laboratory to the clinic. Vision Res. 2013;90:2-9.

6. United Nations. World Population Ageing 2013. New York: UN; 2013. Available from: http://www.un.org/en/development/desa/population/ publications/pdf/ageing/WorldPopulationAgeing2013.pdf. Accessed September 14, 2014

7. Massof RW. A model of the prevalence and incidence of low vision and blindness among adults in the US. Optom Vis Sci. 2002;79(1): 31-38.

8. Blumenkranz MS. Optimal current and future treatments for diabetic macular oedema. Eye (Lond). 2010;24(3):428-434.

9. Danaei G, Finucane MM, Lin JK, et al. National, regional, and global trends in systolic blood pressure since 1980: systematic analysis of health examination surveys and epidemiological studies with 786 country-years and 5.4 million participants. Lancet. 2011;377(9765): $568-577$.

10. Hood DC, Raza AS, de Moraes CG, Liebmann JM, Ritch R. Glaucomatous damage of the macula. Prog Retin Eye Res. 2013;32:1-21.

11. Hood DC, Nguyen M, Ehrlich AC, et al. A test of a model of glaucomatous damage of the macula with high-density perimetry: implications for the locations of visual field test points. Transl Vis Sci Technol. 2014;19;3(3):5.

12. Furtado JM, Lansingh VC, Carter MJ, et al. Causes of blindness and visual impairment in Latin America. Surv Ophthalmol. 2012;57(2): 149-177.
13. Cuadros J, Bresnick G. EyePACS: an adaptable telemedicine system for diabetic retinopathy screening. J Diabetes Sci Technol. 2009;3(3): 509-516.

14. Litvin TV, Ozawa GY, Bresnick GH, et al. Utility of hard exudates for the screening of macular edema. Optom Vis Sci. 2014;91(4): 370-375.

15. International Diabetes Federation. IDF Diabetes Atlas. 6th ed. Brussels: IDF; 2013. Available from: http://www.idf.org/diabetesatlas. Accessed September 20, 2014.

16. Whiting DR, Guariguata L, Weil C, Shaw J. IDF Diabetes Atlas: global estimates of the prevalence of diabetes for 2011 and 2030. Diabetes Res Clin Pract. 2011;94(3):311-321.

17. Guariguata L, Whiting D, Weil C, Unwin N. The International Diabetes Federation Diabetes Atlas methodology for estimating global and national prevalence of diabetes in adults. Diabetes Res Clin Pract. 2011;94(3):322-332.

18. Goto A, Goto M, Noda M, Tsugane S. Incidence of type 2 diabetes in Japan: a systematic review and meta-analysis. PLoS One. 2013;8(9): e74699.

19. Fong DS, Aiello LP, Ferris FL 3rd, Klein R. Diabetic retinopathy. Diabetes Care. 2004;27(10):2540-2553.

20. Olayiwola JN, Sobieraj DM, Kulowski K, St Hilaire D, Huang JJ. Improving diabetic retinopathy screening through a statewide telemedicine program at a large federally qualified health center. J Health Care Poor Underserved. 2011;22(3):804-816.

21. Centers for Disease Control and Prevention. Improving the Nation's Vision Health: A Coordinated Public Health Approach. Atlanta: CDC; 2006. Available from: http://www.cdc.gov/visionhealth/pdf/ improving_nations_vision_health.pdf. Accessed December 18, 2014.

22. Zhang X, Saaddine JB, Chou CF, et al. Prevalence of diabetic retinopathy in the United States, 2005-2008. JAMA. 2010;304(6):649-656.

23. Appiah AP, Ganthier R Jr, Watkins N. Delayed diagnosis of diabetic retinopathy in black and Hispanic patients with diabetes mellitus. Ann Ophthalmol. 1991;23(4):156-158.

24. Varma R, Torres M, Peña F, Klein R, Azen SP. Prevalence of diabetic retinopathy in adult Latinos: the Los Angeles Latino eye study. Ophthalmology. 2004;111(7):1298-1306.

25. Sivaprasad S, Gupta B, Crosby-Nwaobi R, Evans J. Prevalence of diabetic retinopathy in various ethnic groups: a worldwide perspective. Surv Ophthalmol. 2012;57(4):347-370.

26. Heng LZ, Comyn O, Peto T, et al. Diabetic retinopathy: pathogenesis, clinical grading, management and future developments. Diabet Med. 2013;30(6):640-650.

27. Ghanchi F. The Royal College of Ophthalmologists' clinical guidelines for diabetic retinopathy: a summary. Eye (Lond). 2013;27(2): 285-287.

28. Barber AJ, Antonetti DA. Mapping the blood vessels with paracellular permeability in the retinas of diabetic rats. Invest Ophthalmol Vis Sci. 2003;44(12):5410-5416.

29. Antonetti DA, Barber AJ, Bronson SK, et al. Diabetic retinopathy: seeing beyond glucose-induced microvascular disease. Diabetes. 2006;55(9):2401-2411.

30. [No authors listed]. Grading diabetic retinopathy from stereoscopic color fundus photographs - an extension of the modified Airlie House classification. ETDRS report number 10. Early Treatment Diabetic Retinopathy Study Research Group. Ophthalmology. 1991;98(5 Suppl): 786-806.

31. Wilkinson CP, Ferris FL 3rd, Klein RE. Proposed international clinical diabetic retinopathy and diabetic macular edema disease severity scales. Ophthalmology. 2003;110(9):1677-1682.

32. Chew EY, Klein ML, Ferris FL 3rd, et al. Association of elevated serum lipid levels with retinal hard exudate in diabetic retinopathy. Early Treatment Diabetic Retinopathy Study (ETDRS) Report 22. Arch Ophthalmol. 1996;114(9):1079-1084.

33. Silva PS, Cavallerano JD, Tolls D, et al. Potential efficiency benefits of nonmydriatic ultrawide field retinal imaging in an ocular telehealth diabetic retinopathy program. Diabetes Care. 2014;37(1):50-55. 
34. Silva PS, Cavallerano JD, Sun JK, Soliman AZ, Aiello LM, Aiello LP. Peripheral lesions identified by mydriatic ultrawide field imaging: distribution and potential impact on diabetic retinopathy severity. Ophthalmology. 2013;120(12):2587-2595.

35. Nirmalan PK, Katz J, Robin AL, et al. Prevalence of vitreoretinal disorders in a rural population of southern India: the Aravind Comprehensive Eye Study. Arch Ophthalmol. 2004;122(4):581-586.

36. Elsner AE, Muller MS. Laser applications and system considerations in ocular imaging. Laser Photon Rev. 2008;2(5):350-376.

37. Kwan AS, Barry C, McAllister IL, Constable I. Fluorescein angiography and adverse drug reactions revisited: the Lions Eye experience. Clin Experiment Ophthalmol. 2006;34(1):33-38.

38. Hope-Ross M, Yannuzzi LA, Gragoudas ES, et al. Adverse reactions due to indocyanine green. Ophthalmology. 1994;101(3):529-533.

39. Elsner AE, Petrig BL, Papay JA, Kollbaum EJ, Clark CA, Muller MS Fixation stability and scotoma mapping for patients with low vision. Optom Vis Sci. 2013;90(2):164-173.

40. Muller MS, Elsner AE, Ozawa GY. Non-mydriatic confocal retinal imaging using a digital light projector. Proc SPIE. 2013:8567.

41. Aspelund $\mathrm{T}$, Thornórisdóttir O, Olafsdottir E, et al. Individual risk assessment and information technology to optimise screening frequency for diabetic retinopathy. Diabetologia. 2011;54(10): $2525-2532$.

42. van der Heijden AA, Walraven I, van 't Riet E, et al. Validation of a model to estimate personalised screening frequency to monitor diabetic retinopathy. Diabetologia. 2014;57(7):1332-1338.

43. Weber A, Cheney M, Smithwick Q, Elsner A. Polarimetric imaging and blood vessel quantification. Opt Express. 2004;12(21) 5178-5190.

44. Beausencourt E, Remky A, Elsner AE, Hartnett ME, Trempe CL. Infrared scanning laser tomography of macular cysts. Ophthalmology. 2000;107(2):375-385.

45. Remky A, Beausencourt E, Hartnett ME, Trempe CL, Arend O, Elsner AE. Infrared imaging of cystoid macular edema. Graefes Arch Clin Exp Ophthalmol. 1999;237(11):897-901.

46. Williams DR. Imaging single cells in the living retina. Vision Res. 2011; 51(13):1379-1396.

47. Berrio E, Tabernero J, Artal P. Optical aberrations and alignment of the eye with age. JVis. 2010;10(14):34.

48. McLellan JS, Marcos S, Burns SA. Age related changes in monochromatic wave aberrations of the human eye. Invest Ophthalmol Vis Sci. 2001;42(6):1390-1395.

49. [No authors listed]. Photocoagulation for diabetic macular edema. Early Treatment Diabetic Retinopathy Study report number 1. Early Treatment Diabetic Retinopathy Study Research Group. Arch Ophthalmol. 1985;103(12):1796-1806.

50. Wong TY, Klein R, Islam FM, et al. Diabetic retinopathy in a multiethnic cohort in the United States. Am J Ophthalmol. 2006;141(3): 446-455.

51. Curcio CA, Messinger JD, Sloan KR, Mitra A, McGwin G, Spaide RF. Human chorioretinal layer thicknesses measured in macula-wide, highresolution histologic sections. Invest Ophthalmol Vis Sci. 2011;52(7): 3943-3954.

52. Staurenghi G, Sadda S, Chakravarthy U, Spaide RF. Proposed lexicon for anatomic landmarks in normal posterior segment spectral-domain optical coherence tomography: the IN•OCT consensus. Ophthalmology. 2014;121(8):1572-1578

53. Trichonas G, Kaiser PK. Optical coherence tomography imaging of macular oedema. Br J Ophthalmol. 2014;98 Suppl 2:ii24-ii29.

54. Liu MM, Wolfson Y, Bressler SB, Do DV, Ying HS, Bressler NM. Comparison of time- and spectral-domain optical coherence tomography in management of diabetic macular edema. Invest Ophthalmol Vis Sci. 2014;55(3):1370-1377.

55. Sun JK, Lin MM, Lammer J, et al. Disorganization of the retinal inner layers as a predictor of visual acuity in eyes with centerinvolved diabetic macular edema. JAMA Ophthalmol. 2014;132(11): 1309-1316.
56. Schneider EW, Mruthyunjaya P, Talwar N, Harris Nwanyanwu K, Nan $\mathrm{B}$, Stein JD. Reduced fluorescein angiography and fundus photography use in the management of neovascular macular degeneration and macular edema during the past decade. Invest Ophthalmol Vis Sci. 2014;55(1):542-549.

57. Sim DA, Keane PA, Fung S, et al. Quantitative analysis of diabetic macular ischemia using optical coherence tomography. Invest Ophthalmol Vis Sci. 2014;55(1):417-423.

58. Kelly SP, Wallwork I, Haider D, Qureshi K. Teleophthalmology with optical coherence tomography imaging in community optometry. Evaluation of a quality improvement for macular patients. Clin Ophthalmol. 2011;5:1673-1678.

59. Jia Y, Bailey ST, Wilson DJ, et al. Quantitative optical coherence tomography angiography of choroidal neovascularization in age-related macular degeneration. Ophthalmology. 2014;121(7):1435-1444.

60. Hong YJ, Miura M, Ju MJ, Makita S, Iwasaki T, Yasuno Y. Simultaneous investigation of vascular and retinal pigment epithelial pathologies of exudative macular diseases by multifunctional optical coherence tomography. Invest Ophthalmol Vis Sci. 2014;22;55(8): 5016-5031.

61. Harrison WW, Bearse MA Jr, Schneck ME, et al. Prediction, by retinal location, of the onset of diabetic edema in patients with nonproliferative diabetic retinopathy. Invest Ophthalmol Vis Sci. 2011;52(9): 6825-6831.

62. Dhamdhere KP, Schneck ME, Bearse MA Jr, Lam W, Barez S, Adams AJ. Assessment of macular function using the SKILL Card in adults with type 2 diabetes mellitus. Invest Ophthalmol Vis Sci. 2014;55(6): 3368-3374.

63. Xu L, Wang Y, LiY, et al. Causes of blindness and visual impairment in urban and rural areas in Beijing: the Beijing Eye Study. Ophthalmology. 2006;113(7):1134. e1-e11.

64. Klein R, Klein BE. The prevalence of age-related eye diseases and visual impairment in aging: current estimates. Invest Ophthalmol Vis Sci. 2013;54(14):ORSF5-ORSF13.

65. Anderson DH, Radeke MJ, Gallo NB, et al. The pivotal role of the complement system in aging and age-related macular degeneration: hypothesis re-visited. Prog Retin Eye Res. 2010;29(2):95-112.

66. Pikuleva IA, Curcio CA. Cholesterol in the retina: the best is yet to come. Prog Retin Eye Res. 2014;41:64-89.

67. Ooto S, Vongkulsiri S, Sato T, Suzuki M, Curcio CA, Spaide RF. Outer retinal corrugations in age-related macular degeneration. JAMA Ophthalmol. 2014;132(7):806-813.

68. Ferris FL 3rd, Wilkinson CP, Bird A, et al. Clinical classification of agerelated macular degeneration. Ophthalmology. 2013;120(4):844-851.

69. Hartnett ME, Weiter JJ, Staurenghi G, Elsner AE. Deep retinal vascular anomalous complexes in advanced age-related macular degeneration. Ophthalmology. 1996;103(12):2042-2053.

70. Liu L, Swanson M. Improving patient outcomes: role of the primary care optometrist in the early diagnosis and management of age-related macular degeneration. Clin Optom. 2013;5:1-12.

71. Elsner AE, Burns SA, Weiter JJ, Delori FC. Infrared imaging of subretinal structures in the human ocular fundus. Vision Res. 1996;36(1): 191-205.

72. Hartnett ME, Elsner AE. Characteristics of exudative age-related macular degeneration determined in vivo with confocal and indirect infrared imaging. Ophthalmology. 1996;103(1):58-71.

73. Miura M, Elsner AE, Beausencourt E, et al. Grading of infrared confocal scanning laser tomography and video displays of digitized color slides in exudative age-related macular degeneration. Retina. 2002;22(3): 300-308.

74. Farsiu S, Chiu SJ, O'Connell RV, et al. Quantitative classification of eyes with and without intermediate age-related macular degeneration using optical coherence tomography. Ophthalmology. 2014;121(1): $162-172$.

75. Schmitz-Valckenberg S1, Fleckenstein M, Scholl HP, Holz FG. Fundus autofluorescence and progression of age-related macular degeneration. Surv Ophthalmol. 2009;54(1):96-117. 
76. Bindewald A, Bird AC, Dandekar SS, et al. Classification of fundus autofluorescence patterns in early age-related macular disease. Invest Ophthalmol Vis Sci. 2005;46(9):3309-3314.

77. Einbock W, Moessner A, Schnurrbusch UE, Holz FG, Wolf S. Changes in fundus autofluorescence in patients with age-related maculopathy. Correlation to visual function: a prospective study. Graefes Arch Clin Exp Ophthalmol. 2005;243(4):300-305.

78. Hunter JJ, Morgan JI, Merigan WH, Sliney DH, Sparrow JR, Williams DR. The susceptibility of the retina to photochemical damage from visible light. Prog Retin Eye Res. 2012;31(1):28-42.

79. Heimes B, Lommatzsch A, Zeimer M, et al. Long-term visual course after anti-VEGF therapy for exudative AMD in clinical practice evaluation of the German reinjection scheme. Graefes Arch Clin Exp Ophthalmol. 2011;249(5):639-644.

80. Grunwald JE, Daniel E, Huang J, et al. Risk of geographic atrophy in the comparison of age-related macular degeneration treatments trials. Ophthalmology. 2014;121(1):150-161.

81. Verhoeven VJ, Wong KT, Buitendijk GH, Hofman A, Vingerling JR, Klaver CC. Visual consequences of refractive errors in the general population. Ophthalmology. Epub September 7, 2014.

82. Mutti DO, Gwiazda J, Norton TT, Smith EL 3rd, Schaeffel F, To CH. Myopia - yesterday, today, and tomorrow. Optom Vis Sci. 2013;90(11): 1161-1164.

83. Pai AS, Wang JJ, Samarawickrama C, et al. Prevalence and risk factors for visual impairment in preschool children the Sydney Paediatric Eye Disease Study. Ophthalmology. 2011;118(8):1495-1500.

84. Tarczy-Hornoch K, Cotter SA, Borchert M, et al. Prevalence and causes of visual impairment in Asian and non-Hispanic white preschool children: Multi-ethnic Pediatric Eye Disease Study. Ophthalmology. 2013;120(6):1220-1226.

85. Miller JM, Lessin HR. Instrument-based pediatric vision screening policy statement. Pediatrics. 2012;130(5):983-986.

86. Irsch K, Gramatikov BI, Wu YK, Guyton DL. New pediatric vision screener employing polarization-modulated, retinal-birefringencescanning-based strabismus detection and bull's eye focus detection with an improved target system: opto-mechanical design and operation. J Biomed Opt. 2014;19(6):067004.

87. Jost RM, Yanni SE, Beauchamp CL, et al. Beyond screening for risk factors: objective detection of strabismus and amblyopia. JAMA Ophthalmol. 2014;132(7):814-820.

88. Good WV, Hardy RJ, Dobson V, et al. The incidence and course of retinopathy of prematurity: findings from the Early Treatment for Retinopathy of Prematurity study. Pediatrics. 2005;116(1):15-23.

89. Quinn GE, Gilbert C, Darlow BA, Zin A. Retinopathy of prematurity: an epidemic in the making. Chin Med J (Engl). 2010;123(20): 2929-2937.

90. Scott KE, Kim DY, Wang L, et al. Telemedical diagnosis of retinopathy of prematurity intraphysician agreement between ophthalmoscopic examination and image-based interpretation. Ophthalmology. 2008;115(7):1222-1228. e3.

91. Quinn GE, Dobson V, Davitt BV, et al. Progression of myopia and high myopia in the Early Treatment for Retinopathy of Prematurity study: findings at 4 to 6 years of age. JAAPOS. 2013;17(2):124-128.

92. Hammer DX, Iftimia NV, Ferguson RD, et al. Foveal fine structure in retinopathy of prematurity: an adaptive optics Fourier domain optical coherence tomography study. Invest Ophthalmol Vis Sci. 2008;49(5): 2061-2070.

93. Ran X, Cai WJ, Huang XF, et al. 'RetinoGenetics': a comprehensive mutation database for genes related to inherited retinal degeneration. Database (Oxford). Epub June 17, 2014.

94. Beck RW, Moke PS, Turpin AH, et al. A computerized method of visual acuity testing: adaptation of the Early Treatment of Diabetic Retinopathy study testing protocol. Am J Ophthalmol. 2003;135(2): 194-205.

95. Martin DF, Maguire MG, Ying GS, Grunwald JE, Fine SL, Jaffe GJ. Ranibizumab and bevacizumab for neovascular agerelated macular degeneration. $N$ Engl J Med. 2011;364(20): 1897-1908.
96. Mayer MJ, Ward B, Klein R, Talcott JB, Dougherty RF, Glucs A. Flicker sensitivity and fundus appearance in pre-exudative age-related maculopathy. Invest Ophthalmol Vis Sci. 1994;35(3):1138-1149.

97. Dimitrov PN, Robman LD, Varsamidis M, et al. Visual function tests as potential biomarkers in age-related macular degeneration. Invest Ophthalmol Vis Sci. 2011;52(13):9457-9469.

98. Faes L, Bodmer NS, Bachmann LM, Thiel MA, Schmid MK. Diagnostic accuracy of the Amsler grid and the preferential hyperacuity perimetry in the screening of patients with age-related macular degeneration: systematic review and meta-analysis. Eye (Lond). 2014;28(7):788-796.

99. Pelli DG, Bex P. Measuring contrast sensitivity. Vision Res. 2013;90: $10-14$.

100. Zimmerman AB, Lust KL, Bullimore MA. Visual acuity and contrast sensitivity testing for sports vision. Eye Contact Lens. 2011;37(3): 153-159.

101. Schneck ME, Haegerstrom-Portnoy G, Lott LA, Brabyn JA, Gildengorin G. Low contrast vision function predicts subsequent acuity loss in an aged population: the SKI study. Vision Res. 2004; 44(20):2317-2325.

102. Bailey IL, Jackson AJ, Minto H, Greer RB, Chu MA. The Berkeley Rudimentary Vision Test. Optom Vis Sci. 2012;89(9):1257-1264.

103. Song H, Chui TY, Zhong Z, Elsner AE, Burns SA. Variation of cone photoreceptor packing density with retinal eccentricity and age. Invest Ophthalmol Vis Sci. 2011;52(10):7376-7384.

104. Chui TY, Song H, Clark CA, Papay JA, Burns SA, Elsner AE. Cone photoreceptor packing density and the outer nuclear layer thickness in healthy subjects. Invest Ophthalmol Vis Sci. 2012;53(7): 3545-3553.

105. Enoch JM. "Gold standards" for vision testing. Invest Ophthalmol Vis Sci. 1998;39(8):1297-1299.

106. Chew EY, Clemons TE, Bressler SB, et al. Randomized trial of a home monitoring system for early detection of choroidal neovascularization Home Monitoring of the Eye (HOME) study. Ophthalmology. 2014;121(2):535-544.

107. Kollbaum PS, Jansen ME, Kollbaum EJ, Bullimore MA. Validation of an iPad test of letter contrast sensitivity. Optom Vis Sci. 2014;91(3): 291-296.

108. Turpin A, Lawson DJ, McKendrick AM. PsyPad: a platform for visual psychophysics on the iPad. J Vis. 2014;14(3):16.

109. Timberlake GT, Mainster MA, Peli E, Augliere RA, Essock EA, Arend LE. Reading with a macular scotoma. I. Retinal location of scotoma and fixation area. Invest Ophthalmol Vis Sci. 1986;27(7): 1137-1147.

110. Amore FM, Fasciani R, Silvestri V, et al. Relationship between fixation stability measured with MP-1 and reading performance. Ophthalmic Physiol Opt. 2013;33(5):611-617.

111. Pokorny J, Smith VC, Lutze M. Aging of the human lens. Appl Opt. 1987;26(8):1437-1440.

112. Rocha KM, Nosé W, Bottós K, Bottós J, Morimoto L, Soriano E. Higher-order aberrations of age-related cataract. $J$ Cataract Refract Surg. 2007;33(8):1442-1446.

113. Delori FC, Pflibsen KP. Spectral reflectance of the human ocular fundus. Appl Opt. 1989;28(6):1061-1077.

114. Winn B, Whitaker D, Elliott DB, Phillips NJ. Factors affecting lightadapted pupil size in normal human subjects. Invest Ophthalmol Vis Sci. 1994;35(3):1132-1137.

115. Yang Y, Thompson K, Burns SA. Pupil location under mesopic, photopic, and pharmacologically dilated conditions. Invest Ophthalmol Vis Sci. 2002;43(7):2508-2512.

116. Jacobs RJ, Bailey IL, Bullimore MA. Artificial pupils and Maxwellian view. Appl Opt. 1992;31(19):3668-3677.

117. Dacey DM, Liao HW, Peterson BB, et al. Melanopsin-expressing ganglion cells in primate retina signal colour and irradiance and project to the LGN. Nature. 2005;433(7027):749-754.

118. Gamlin PD, McDougal DH, Pokorny J, Smith VC, Yau KW, Dacey DM. Human and macaque pupil responses driven by melanopsin-containing retinal ganglion cells. Vision Res. 2007;47(7):946-954. 
119. Brown TM, Gias C, Hatori M, et al. Melanopsin contributions to irradiance coding in the thalamo-cortical visual system. PLoS Biol. 2010;8(12):e1000558.

120. Lei S, Goltz HC, Chandrakumar M, Wong AM. Full-field chromatic pupillometry for the assessment of the postillumination pupil response driven by melanopsin-containing retinal ganglion cells. Invest Ophthalmol Vis Sci. 2014;55(7):4496-4503.

121. Elsner AE, Burns SA, Beausencourt E, Weiter JJ. Foveal cone photopigment distribution: small alterations associated with macular pigment distribution. Invest Ophthalmol Vis Sci. 1998;39(12):2394-2404.

122. Koo E, Neuringer M, SanGiovanni JP. Macular xanthophylls, lipoprotein-related genes, and age-related macular degeneration. Am J Clin Nutr. 2014;100 Suppl 1:336S-346S.

123. Delori FC, Goger DG, Hammond BR, Snodderly DM, Burns SA Macular pigment density measured by autofluorescence spectrometry: comparison with reflectometry and heterochromatic flicker photometry. J Opt Soc Am A Opt Image Sci Vis. 2001;18(6):1212-1230.

124. Bedford RE, Wyszecki GW. Axial chromatic aberration of the human eye. J Opt Soc Am. 1957;47(6):564-565.

125. Charman WN, Jennings JA. Objective measurements of longitudinal chromatic aberration of human eye. Vision Res. 1976;16(9): 999-1005.

126. Sivak JG, Mandelman T. Chromatic dispersion of the ocular media. Vision Res. 1982;22(8):997-1003.

127. Marcos S, Burns SA, Moreno-Barriusop E, Navarro R. A new approach to the study of ocular chromatic aberrations. Vision Res. 1999;39(26):4309-4323.

128. Fernández EJ, Unterhuber A, Povazay B, Hermann B, Artal P, Drexler W. Chromatic aberration correction of the human eye for retina imaging in the near infrared. Opt Express. 2006;14(13):6213-6225.

129. Liu Z, Kocaoglu OP, Miller DT. In-the-plane design of an off-axis ophthalmic adaptive optics system using toroidal mirrors. Biomed Opt Express. 2013;4(12):3007-3029.

130. Ogboso YU, Bedell HE. Magnitude of lateral chromatic aberration across the retina of the human eye. J Opt Soc Am A. 1987;4(8): 1666-1672.

131. Johnson CA, Casson EJ. Effects of luminance, contrast, and blur on visual acuity. Optom Vis Sci. 1995;72(12):864-869.

132. Coletta NJ, Sharma V. Effects of luminance and spatial noise on interferometric contrast sensitivity. J Opt Soc Am A Opt Image Sci Vis. 1995;12(10):2244-2251.

133. Fitzke FW. Dark adaptation in retinal abnormalities. Br J Ophthalmol. 1994;78(6):426.

134. Hood DC. Lower-level visual processing and models of light adaptation. Annu Rev Psychol. 1998;49:503-535.

135. Kalloniatis M, Luu C. Webvision: Light and dark adaptation. 2007. Available from: http://webvision.med.utah.edu/book/part-viii-gabacreceptors/light-and-dark-adaptation. Accessed October 8, 2014.

136. Elsner AE, Burns SA, Lobes LA Jr. Foveal cone optical density in retinitis pigmentosa. Appl Opt. 1987;26(8):1378-1384.

137. Burns SA, Elsner AE, Lobes LA Jr. Foveal cone photopigment bleaching in central serous retinopathy. Appl Opt. 1987;27(6):1045-1049.

138. Elsner AE, Berk L, Burns SA, Rosenberg PR. Aging and human cone photopigments. J Opt Soc Am A. 1988;5(12):2106-2112.

139. Wu J, Seregard S, Algvere PV. Photochemical damage of the retina. Surv Ophthalmol. 2006;51(5):461-481.

140. Delori FC, Webb RH, Sliney DH. Maximum permissible exposure for ocular safety (ANSI 2000), with emphasis on ophthalmic devices. J Opt Soc Am A Opt Image Sci Vis. 2007;24(5):1250-1265.
141. Navarro R. The optical design of the human eye: a critical review. J Optom. 2009;2(1):3-18.

142. Newton MJ. The promise of telemedicine. Surv Ophthalmol. 2014;59(5):559-567.

143. Lord RK, Shah VA, San Filippo AN, Krishna R. Novel uses of smartphones in ophthalmology. Ophthalmology. 2010;117(6):1274-1274.

144. Teichman JC, Sher JH, Ahmed IIK. From iPhone to eyePhone: a technique for photodocumentation. Can J Ophthalmol. 2011;46(3): 284-286

145. Chakrabarti D. Application of mobile technology in ophthalmology to meet the demands of low-resource settings. J Mob Technol Med. 2012;1(4):1-3.

146. Bastawrous A. Smartphone fundoscopy. Ophthalmology. 2012;119(2) 432-433.

147. Vinekar A, Gilbert C, Dogra M, et al. The KIDROP model of combining strategies for providing retinopathy of prematurity screening in underserved areas in India using wide-field imaging, tele-medicine, non-physician graders and smart phone reporting. Indian JOphthalmol. 2014;62(1):41-49.

148. Kim DY, Delori F, Mukai S. Smartphone photography safety. Ophthalmology. 2012;119(10):2200-2201.

149. Li Z, Wu C, Olayiwola JN, Hilaire DS, Huang JJ. Telemedicine-based digital retinal imaging vs standard ophthalmologic evaluation for the assessment of diabetic retinopathy. Conn Med. 2012;76(2):85-90.

150. Joslin Vision Network [homepage on the Internet]. Available from: http://www.joslin.org/joslin_vision_network.html. Accessed October 8, 2014.

151. Hautala N, Riittaliisa A, Korpelainen J, et al. Marked reductions in visual impairment due to diabetic retinopathy achieved by efficient screening and timely treatment. Acta Ophthalmol. 2014;92(60): $582-587$.

152. Horner DG. Adventures in humanitarian eyecare. Indiana J Optom. 2007;10(1):19-25.

153. Gupta V, Bansal R, Gupta A, Bhansali A. Sensitivity and specificity of nonmydriatic digital imaging in screening diabetic retinopathy in Indian eyes. Indian J Ophthalmol. 2014;62(8):851-556.

154. Rao GN, Khanna RC, Athota SM, Rajshekar V, Rani PK. Integrated model of primary and secondary eye care for underserved rural areas: the L V Prasad Eye Institute experience. Indian J Ophthalmol. 2012;60(5):396-400.

155. Namperumalsamy P, Nirmalan PK, Ramasamy K. Developing a screening program to detect sight-threatening diabetic retinopathy in South India. Diabetes Care. 2003;26(6):1831-1835.

156. Namperumalsamy P, Kim R, Kaliaperumal K, Sekar A, Karthika A, Nirmalan PK. A pilot study on awareness of diabetic retinopathy among non-medical persons in South India. The challenge for eye care programmes in the region. Indian J Ophthalmol. 2004;52(3):247-251.

157. Zimmer-Galler IE, Zeimer R. Telemedicine in diabetic retinopathy screening. Int Ophthalmol Clin. 2009;49(2):75-86.

158. Benbassat J, Polak BC. Reliability of screening methods for diabetic retinopathy. Diabet Med. 2009;26(8):783-790.

159. British Diabetic Association. Retinal Photography Screening for Diabetic Eye Disease. London: BDA; 1997.

160. Horner DG, Thibos L, Jennifer Page J, Perotti J, Kollbaum P, Peabody T. Real cost of recycled spectacles. Optom Vis Sci. 2012; 89(11):e95-e96.

161. Chakravarthy U, Wong TY, Fletcher A, et al. Clinical risk factors for age-related macular degeneration: a systematic review and meta-analysis. BMC Ophthalmol. 2010;10:31. 


\section{Publish your work in this journal}

Clinical Optometry is an international, peer-reviewed, open access journal publishing original research, basic science, clinical and epidemiological studies, reviews and evaluations on clinical optometry. All aspects of patient care are addressed within the journal as well as the practice of optometry including economic and business analyses. Basic and clinical

Submit your manuscript here: http://www.dovepress.com/clinical-optometry-journal

research papers are published that cover all aspects of optics, refraction and its application to the theory and practice of optometry. The manuscript management system is completely online and includes a very quick and fair peer-review system, which is all easy to use. Visit http://www.dovepress. com/testimonials.php to read real quotes from published authors. 